\title{
THE EFFECT OF TRICHLOROETHENE \\ ON THE AQUEOUS SOLUBILITY OF CHLOROBENZENES
}

by

Chunming Yu

\author{
A Thesis Submitted to the Faculty of the \\ DEPARTMENT OF HYDROLOGY AND WATER RESOURCES \\ In Partial Fulfillment of the Requirements \\ For the Degree of \\ MASTER OF SCIENCE \\ WITH A MAJOR IN HYDROLOGY \\ In the Graduate College \\ THE UNIVERSITY OF ARIZONA
}

1993 


\section{STATEMENT BY AUTHOR}

This thesis has been submitted in partial fulfillment of requirements for an advanced degree at The University of Arizona and is deposited in the Hydrology and Water Resource Department to be made available to borrowers under rules of the Department.

Brief quotations from this thesis are allowable without special permission, provided that accurate acknowledgment of source is made. Requests for permission for extended quotation from or reproduction of this manuscript in whole or in part may be granted by the copyright holder.

SIGNED:

APPROVAL BY THESIS DIRECTORS

This thesis has been approved in the date shown below: 


\section{ACKNOWLEDGEMENTS}

I would like to express my appreciation to Dr. Martha Conklin, who supported me during the entire research by providing necessary graduate assistantship and by giving valuable academic advice. My understanding of the topic started from graduate years. I am deeply grateful to Dr. Martha Conklin for her enthusiastic encouragement, patient guidance, and heartily sympathy.

I would also like to express my appreciation to Dr. Jim Yeh, who gave me opportunity and financial support for me to begin graduate study.

I would like to thank Tim Curley and Robert Matzner for their helpful advice and valuable assistance during the laboratory work. In addition, I want to thank Dr. Samuel Yalkowsky and Paul Myrdal from College of Pharmacy for the experiment setup and the in-depth discussion.

Finally, I would like to thank my parents and husband for their support throughout my academic career, particularly during my early graduate study. Without their volunteerly taking care of my daughter in China, it was not possible for me to be a graduate student in this country and this thesis could not have been completed. 
TABLE OF CONTENTS

LIST OF FIGURES

LIST OF TABLES . . . . . . . . . . . . . . . . . 8

ABSTRACT . . . . . . . . . . . . . . . . . 9

INTRODUCTION . . . . . . . . . . . . . . . . . . 10

BACKGROUND . . . . . . . . . . . . . . . . . 14

2.1 Solubility of Organic Compounds . . . . . . . . . . 14

2.1.1 Liquid Solute . . . . . . . . . . . . . . . 14

2.1.2 Solid Solute . . . . . . . . . . . . . . 16

2.2 Solubility of Mixtures . . . . . . . . . . . . . 17

2.2.1 Mixtures of Liquid in Liquid . . . . . . . . . . 17

2.2.2 Mixtures of Solid in Liquid . . . . . . . . . . . 19

2.3 Accommodation . . . . . . . . . . . . . 21

2.4 Physical and Chemical Properties of Studied Compounds . . . . 22

METHODS AND MATERIALS . . . . . . . . . . . . . 24

3.1 Chemicals and Apparatus . . . . . . . . . . . . 24

3.2 Batch Experiments . . . . . . . . . . . . . . . 26

3.2.1 Aqueous Solubility of Pure Compounds . . . . . . . 26

3.2.1.1 Experimental Set-up . . . . . . . . . . 26

3.2.1.2 Standard Calibration Curve . . . . . . . . . 27

3.2.1.3 Sample Analysis . . . . . . . . . . . . 27

3.2.2 Aqueous Solubilities of Mixtures . . . . . . . . 28

RESULTS . . . . . . . . . . . . . . . . 32

4.1 Results of Solubilities . . . . . . . . . . . . 32

4.2 Effect of TCE on the Solubility of Chlorobenzenes . . . . . . 32 


\section{TABLE OF CONTENTS - Continued}

4.2.1 Effect of TCE on the Solubility of Liquid

Chlorobenzenes . . . . . . . . . . . . . . . 32

4.2.2 Effect of TCE on the Solubility of Solid

Chlorobenzenes . . . . . . . . . . . . . . 34

4.2.3 Solubility in Mixtures . . . . . . . . . . . 42

4.3 Apparent Solubilities . . . . . . . . . . . . . . . 42

4.3.1 Accommodation and Apparent Solubilities . . . . . . 42

4.3.2 Solubility Determination from Apparent

Solubilities . . . . . . . . . . . . . . . . . . 45

4.3.3 Apparent Solubilities of Mixtures . . . . . . . . 47

DISCUSSION . . . . . . . . . . . . . . . 54

5.1 Error Analysis . . . . . . . . . . . . . . . 54

5.2 Equilibrium Model . . . . . . . . . . . . . 55

5.2.1 Mixtures of Liquid Chlorobenzene and TCE . . . . . . 55

5.2.2 Mixtures of Solid Chlorobenzene and TCE . . . . . . 65

5.3 Phenomenon Explanation and Application . . . . . . . 70

5.4 Real or Apparent Solubility . . . . . . . . . . . 71

CONCLUSION . . . . . . . . . . . . . . 73

REFERENCES . . . . . . . . . . . . . . . . 75 


\section{LIST OF FIGURES}

Figure 3.1. Losses of TCE calculated from TCE blank solution. . . . . 30

Figure 4.1. Solubilities of monochlorobenzene in the presence of varying amounts of TCE. . . . . . . . . . . . 35

Figure 4.2. Solubilities of 1,2-dichlorobenzene in the presence of varying amounts of TCE. . . . . . . . . . . . . 36

Figure 4.3. Solubilities of 1,3-dichlorobenzene in the presence of varying amounts of TCE. . . . . . . . . . . . . . . 37

Figure 4.4. Solubilities of 1,2,4-trichlorobenzene in the presence of varying amounts of TCE. . . . . . . . . . . . . . 38

Figure 4.5. Concentrations of TCE in the presence of 1,2-DCB. . . . . . 43

Figure 4.6. Apparent solubilities are directly proportional to solute availability in the system. . . . . . . . . . . 44

Figure 4.7. Centrifugation resulted in large escape of dissolved 1,2-DCB from centrifuge tube to the air due to the vacuum formed inside centrifuge. . . . . . . . . . . . . 46

Figure 4.8. Solubility of chlorobenzene as a function of chlorobenzene added to the solution.

Figure 4.9. Apparent solubilities of 1,2-dichlorobenzene with and without TCE.

Figure 4.10. Apparent solubilities of 1,2-dichlorobenzene is inverse proportional to TCE concentration. . . . . . . . . 50

Figure 4.11. Concentration of TCE with and without 1,2-dichlorobenzene in the system.

Figure 4.12. For low concentration of TCE, its concentration is not affected by 1,2-dichlorobenzene in the mixture. . . . . . 53

Figure 5.1. The model fit for monochlorobenzene. . . . . . . . . 56 


\section{LIST OF FIGURES - Continued}

Figure 5.2. The model fit for 1,2-dichlorobenzene. . . . . . . . 57

Figure 5.3. The model fit for 1,3-dichlorobenzene. . . . . . . . . 58

Figure 5.4. The model fit for 1,2,4-trichlorobenzene. . . . . . . . 59 


\section{LIST OF TABLES}

Table 2.1. Physical and chemical properties of studied compounds . . . 23

Table 3.1. Amount of solute used to prepare solutions . . . . . . . . 31

Table 4.1. The Aqueous Solubilities of 7 Chlorobenzenes at $25^{\circ} \mathrm{C}$. . . 33

Table 4.2. Effect of TCE on the solubility of 1,4-dichlorobenzene . . . . 39

Table 4.3. Effect of TCE on the solubility of 1,2,3-dichlorobenzene . . . . 40

Table 4.4. Effect of TCE on the solubility of 1,3,5-dichlorobenzene . . . . 41

Table 5.1. Effect of TCE on the solubility of monochlorobenzene . . . . 61

Table 5.2. Effect of TCE on the solubility of 1,2-dichlorobenzene . . . . 62

Table 5.3. Effect of TCE on the solubility of 1,3-dichlorobenzene . . . . 63

Table 5.4. Effect of TCE on the solubility of 1,2,4-trichlorobenzene . . . . 64

Table 5.5. Hypothetical supercooled liquid solubility estimates at $25^{\circ} \mathrm{C}$. . . . . . . . . . . . . 67

Table 5.6. Aqueous solubility results for 3 solid chlorobenzenes in mixture .............. . 68

Table 5.7. Solubility for mixtures of Chlorobenzene and TCE . . . . . . 69 


\begin{abstract}
Cosolute effects of trichloroethene (TCE) on the solubility of seven chlorobenzenes have been studied. The chlorobenzenes chosen for the study were mono-, di- and trichlorobenzenes. The solubilities of these chlorobenzenes were determined with and without the presence of TCE. TCE concentrations used ranged from 0 to $3300 \mathrm{ppm}$ (above solubility). It has been found that reliable measurements demand relatively long mixing times and settling times to minimize the effect of colloids. Experimental results indicate that (1) most published solubility data for chlorobenzenes are apparent solubilities (i.e., a function of experimental procedures); (2) the solubilities of chlorobenzenes which are liquid at $25{ }^{\circ} \mathrm{C}$ decrease with increasing concentrations of TCE; and (3) TCE does not decrease solubilities of chlorobenzenes which are solid at $25^{\circ} \mathrm{C}$ unless TCE present in the organic phase dissolves the solid chlorobenzene. The model used to predict the co-solute effects on aqueous solubilities indicates that near ideal behavior is observed. These results suggest that chlorobenzene concentrations below solubility do not necessarily indicate the absence of an organic phase.
\end{abstract}




\section{Chapter 1}

\section{INTRODUCTION}

Groundwater migration of organic pollutants from hazardous-waste sites depends on the solubilities of the compounds. A nonpolar organic compound may enter the aquatic environment in its pure form, but it often released as a mixture of other organic solvents which can act as either co-solvents or cosolutes. The behavior of a compound in a mixture may not correspond to that predicted from pure component data. Therefore, the knowledge of solubilities of aqueous mixtures of organic compounds is of particular important to estimate and model the transport of these contaminants.

Aqueous solubilities of hydrophobic organic compounds (HOC) can be enhanced or depressed in the presence of other organic compounds (Eganhouse and Calder, 1976). Predicting the solubility of organic environmental pollutants in mixed solvent systems has become increasingly important in recent years. In complex mixtures, the solution phase may consist of various completely miscible (with water) organic solvents ((CMOSs) or partially miscible (with water) organic solvents (PMOSs). Morris et al. (1988) demonstrated that the solubilities of HOC increased in a log-linear manner in the presence of CMOSs. PMOSs with strong polar functional groups significantly enhance HOC solubility (Pinal et al., 1990). Vadas et al. (1991), however, noticed that the solubilities of HOC's decreased in the presence of another liquid organic compound. 
To predict the behavior of mixture, Banerjee et al. (1984) found that mixtures of structurally related hydrophobic liquids were near ideal (obey Raoults' law) in the organic phase; in the aqueous phase the activity coefficient of a component was unaffected by the presence of co-solutes. In contrast to these results, few studies have been done on effect of nonpolar PMOSs on the solubilities of HOC's, which have different structures. The only available experimental results from Pinal et al. (1990) showed that nonpolar PMOSs (e.g., trichloroethene (TCE)) did not appreciably increase HOC solubility.

The ability to understand and predict the effect of a co-solute upon the solubility and transport of a solute involves an understanding of how the solutes interact in the organic phase as well as in the aqueous phase. Identifying the changed solubility in mixtures is very important to model the transport of contaminant. For this purpose, this work investigated the effect of PMOSs on the solubilities of HOC. The approach chosen was to determine solubilities of chlorobenzenes (HOC) in water as a function of TCE concentration (PMOSs).

TCE, a common industrial solvent, was widely used up to the early 1970 's, and is found at many hazardous-waste sites. Chlorobenzenes, used as intermediates in the manufacture of many pesticides, are classified by the Environmental Protection Agency as hazardous waste, hazardous substance, priority toxic pollutants, and carcinogens (Sittig, 1981). Because these contaminants are a health risk to humans and animals and they are often 
occur in ground water, there is a great interest in predicting transport of these substances in the aquifer.

Solubility data for chlorobenzenes already existed in the literature (e.g., Chey and Calder, 1972; Yalkowsky et al., 1979; Banerjee et al., 1980; Mackay and Shiu, 1981; McNally and Grob, 1983; Yalkowsky et al., 1983; Banerjee, 1984; Miller et al., 1984; and Ruelle et al., 1993). However, accurate determination of solubility are experimentally very difficult for HOC. It can be shown that some experimental solubility data are in error by two orders of magnitude. Thus, to determine reliable solubility data for pure chlorobenzenes is crucial first step to describe the effects of additional compound (TCE) on altering the solubilities of chlorobenzenes.

In this work, solubilities of seven chlorobenzenes, which have melting points both above and below $25^{\circ} \mathrm{C}$, were determined. And then co-solute effects on their solubilities were investigated by varying concentration of TCE from zero ppm to three times of TCE's solubility ( TCE solubility: 1100 ppm). Our preliminary experiments indicated that the presence of TCE decreased solubility, so the least soluble compounds were not studied. This constraint limited the compounds to mono-, di-, and trichlorobenzenes with solubilities above $5 \mathrm{ppm}$. The model to predict co-solute effect from Banerjee (Banerjee, 1984) was evaluated with respect to experimental results. All the experiments in this research were conducted at $25^{\circ} \mathrm{C}$ because several investigators have previously observed and reported that the solubility never varied by more than 2.5 percent between 5 and $25^{\circ} \mathrm{C}$ (May et 
al., 1978, Bohon and Claussen, 1951, et al.).

The purpose of this research is to improve our ability to describe the effects of additional component on the solubilities and thus to provide a model which can be used to predict the transport of aqueous mixtures of organic contaminants in groundwater. 


\section{Chapter 2}

\section{BACKGROUND}

\subsection{Solubility of Organic Compounds}

The aqueous solubility of a solute is defined as the maximum concentration that can be achieved in an equilibrium situation. Organic compounds differ widely in their solubility, from infinitely miscible polar compounds, such as methanol and acetone, to extremely low solubility nonpolar compounds, such as polynuclear aromatic hydrocarbons. In this study, only nonpolar organic compound is considered.

It is well known that poorly soluble compounds dissolve slowly. For example, Haque et al. equilibrated a solution of Aroclor 1254 (a commercial formulation of polychlorinated biphenyls) for two months before full saturation was reached (Yalkowsky and Banerjee, 1992). Because chlorobenzenes are HOC, slow dissolution rate for these compounds is expected.

\subsubsection{Liquid Solute}

The behavior of a solute in solution is governed by its activity, $a$, which is defined as the ratio of its fugacity (or escaping tendency) in the dissolved solution to that in its pure liquid state. The activity relates to concentration $x_{w}$ (in mole fraction units) through activity coefficient $\gamma_{w}$ of a solute: 


$$
\gamma_{w}=\frac{a_{w}}{x_{w}}
$$

where the $w$ subscript represents the water phase. For hydrophobic solute $\gamma_{w}$ is greater than unity. When a liquid solute is in equilibrium with water, the chemical potentials in the aqueous and organic phases must be equal. This equality, in conjunction with the choice of pure (liquid) solute as the standard state and Raoult's law convention for activity coefficients, results in the following expression at equilibrium:

$$
x_{w} \gamma_{w}=x_{o} \gamma_{o}
$$

i.e., the activity of the solute must be equal in both phases; Where the subscript $o$ denote the organic phase. $\gamma_{o}$ is activity coefficient of the chemical in the organic phase in equilibrium with the aqueous phase; and $\gamma_{w}$ is the activity coefficient of chemical in the aqueous phase in equilibrium with the organic phase (Lee et al., 1992). For liquids that are poor solvents for water, the organic phase is essentially the pure liquid solute, and $x_{o}$ and $\gamma_{o}$ can both be approximated by unity (Banerjee, 1984), thus

$$
x_{w}=\frac{1}{\gamma_{w}}
$$

or

$$
\log x_{w}=-\log \gamma_{w}
$$




\subsubsection{Solid Solute}

The above treatment applies only to liquid solutes. The solubility of a crystalline solute in water is given by

$$
\log x_{w}=\log \frac{x^{c}}{x^{s c l}}-\log \gamma_{w}
$$

where the ratio $x^{c} / x^{s c l}$ represents the solubility of a crystalline material $x^{c}$, over that expected for a hypothetical supercooled liquid $x^{s c l}$. This ratio can be determined from the equation

$$
\log \frac{x^{c}}{x^{s c l}}=-\frac{\Delta S_{f}\left(T_{m}-T\right)}{2.303 R T}+\frac{\Delta C_{p}\left(T_{m}-T\right)}{2.303 R T}-\frac{\Delta C_{p} \log \left(T_{m} / T\right)}{R}
$$

where $\Delta S_{f}$ and $\Delta C_{p}$ are the entropy and heat capacity differences between the solid and the liquid forms of the material respectively, $T_{m}$ is the melting point, and $T$ is the temperature of interest, both in ${ }^{\circ} \mathrm{K}$, and $T \leq T_{m}$ (Yalkowsky and Banerjee, 1992). For all practical purposes the crystal to liquid solubility ratio is equivalent to fugacity ratio described by Mackay and Shiu (1977).

The equation (6) can be simplified by eliminating the $\Delta C_{p}$ terms ( that is, assuming $\Delta C_{p}=0$ )

$$
\log \frac{x^{c}}{x^{s c l}}=-\frac{\Delta S_{f}\left(T_{m}-T\right)}{2.303 R T}
$$

This simplified equation has been proved as valid (Yalkowsky, 1992). 
The magnitude of the effect of crystal interaction energy on solubility is dependent primarily upon the melting point of the solute. For rigid molecules at $25^{\circ} \mathrm{C}$ above equation becomes

$$
\log \frac{x^{c}}{x^{s c l}}=-0.00989(M P-25)
$$

where MP is the compound melting point in ${ }^{\circ} \mathrm{C}$. It is obvious from equation (8) that for liquid (which are treated as having an effective melting point of $25^{\circ} \mathrm{C}$ ), the crystal to liquid solubility ratio is equal to unity. For crystalline solutes the crystal to liquid solubility ratio decreases exponentially with melting point (Yalkowsky and Valvani, 1980, Yalkowsky et al., 1983).

\subsection{Solubility of Mixtures}

Contaminants are frequently released to the aquatic environment in mixtures. Many studies have attempted to account for solubility of hydrophobic organic compounds in mixtures. (e.g., Leinonen and Mackay, 1973; Eganhouse and Calder, 1976; Tewari et al., 1982; Banerjee, 1984; Sugatt et al., 1984; Burris and MacIntyre, 1985; Burris and MacIntyre, 1986; Murphy et al., 1987; and Vadas et al., 1991). The following discussion about the solubility of mixtures will be divided into two parts: liquid mixtures and solid-liquid mixtures.

\subsubsection{Mixtures of Liquid in Liquid}

When a mixture of hydrophobic liquids is equilibrated with water, for the mixture of liquids, the $i$ th component can be written as the equilibrium between the organic and aqueous phase, or that the activities of two phases 
are equal:

$$
\left(x_{i}\right)_{w}\left(\gamma_{i}\right)_{w}=\left(x_{i}\right)_{o}\left(\gamma_{i}\right)_{o}
$$

If equation (9) was divided by equation (3), the solubility of this component in the mixture can be expressed as a fraction of its solubility in its pure form

$$
\frac{\left(x_{i}\right)_{w}}{\left(x_{i}^{p}\right)_{w}}=\frac{\left(x_{i}\right)_{o}\left(\gamma_{i}\right)_{o}\left(\gamma_{i}^{p}\right)_{w}}{\left(\gamma_{i}\right)_{w}}
$$

where the "p" superscript represents the pure solute. For most solutes equation (10) can be expressed as

$$
\frac{s_{i}}{S_{i}}=\frac{\left(x_{i}\right)_{o}\left(\gamma_{i}\right)_{o}\left(\gamma_{i}^{p}\right)_{w}}{\left(\gamma_{i}\right)_{w}}
$$

where $s_{i}$ and $S_{i}$ are the aqueous solubilities (in mole fraction) of the $i$ th component as part of a mixture, and as pure compound, respectively. If interaction in the aqueous phase is small, as is typical for all but highly soluble materials, then $\left(\gamma_{i}^{p}\right)_{w} \approx\left(\gamma_{i}\right)_{w}$, and equation (11) reduces to

$$
\frac{s_{i}}{S_{i}}=\left(x_{i}\right)_{o}\left(\gamma_{i}\right)_{o}
$$

this equation means that aqueous concentration of any component in a mixture is governed by two factors: the water solubility of the pure component and the activity of the component in the organic mixture. for the ideal mixture, the activity coefficient approaches unity, and then equation (12) further simplifies to 


$$
\frac{s_{i}}{S_{i}}=\left(x_{i}\right)_{o}
$$

This relation implies that the aqueous solubility of a component in the mixture solely depends on aqueous solubility of that pure component and mole fraction of that component in organic phase and that any interaction between organic components in the aqueous phase is negligible. Equation (13) bears a striking similarity to Raoult's law, the expression relating the partial pressure of a component above a miscible liquid mixture

$$
P_{i}=x_{i} P_{i}^{\text {pure }}
$$

where, $x_{i}$ is mole fraction of component in liquid, $P_{i}$ and $P^{\text {pure }}$ are partial pressure and pure pressure, respectively. It can be seen that the solubility of a component in the mixture tends to decrease with decreasing fraction of that component in organic phase. Equation (13) applies to ideal mixtures, equation (12) corrects for differences in activity coefficient in the organic phase, and equation (11) includes corrections for both organic and aqueous phases (Banerjee, 1984).

\subsubsection{Mixtures of Solid in Liquid}

Mixtures of liquid and solid are more complex, and solubility behavior tends to vary with the proportion of liquid and solid in the mixture. If the liquid solute and solid solute are two phases in the mixture, i.e., solid solute still keeps solid state, the solubilities behave independently of one another, and solubility remains unchanged for solid solute (Banerjee, 1984). If the liquid component in the mixture dissolves the solid, the the mixture behaves 
as a typical mixture of liquids since the solutes can interact in the organic phase. For liquid organic mixtures, the solubility of a component has been shown to obey:

$$
\frac{s_{i}}{S_{i}}=\left(x_{i}\right)_{o}\left(\gamma_{i}\right)_{o}
$$

However, for homogeneous mixture of liquid and solid, it is inappropriate to relate $s_{i}$ for a solute in a liquid mixture to $S_{i}$, its solubility in its pure form, without correcting for the difference in phase, because the solute is a solid when pure, and a liquid when in a mixture. Therefore, its hypothetical supercooled liquid solubility must be used, i.e.,

$$
\frac{s_{i}}{S_{i}^{s c l}}=\left(x_{i}\right)_{o}\left(\gamma_{i}\right)_{o}
$$

$S_{i}^{s c l}$ can be calculated through equation (8). equation (8) is equivalent to

$$
\log \frac{S_{i}}{S_{i}^{s c l}}=-0.00989(M P-25)
$$

in another form, equation (17) is

$$
\log S_{i}^{S c l}=\log S_{i}+0.00989(M P-25)
$$

where $S_{i}^{s c l}$ is hypothetical supercooled liquid solubility and $S_{i}$ is solubility in pure form.

Equation (18) indicates that the supercooled liquid solubility of a solid compound differs from the pure compound solubility by an amount related to 
the energy required in the transition from a solid to a liquid. Therefore, it is essential that the pure compound solubility of the solid be corrected to a hypothetical liquid reference state (Vadas et al., 1991). If we assume that $\left(\gamma_{i}\right)_{o} \approx 1$, equation (16) can be further simplified as

$$
\frac{s_{i}}{S_{i}^{s c l}}=\left(x_{i}\right)_{o}
$$

Equation (19) applies to ideal mixture of liquid and solid where the solid solute dissolves in liquid solute, and equation (16) corrects for differences in activity coefficient in the organic phase.

\subsection{Accommodation}

The aqueous solubility is a fundamental parameter in assessing the extent dissolution of $\mathrm{HOC}$ and their persistence in the environment. Any attempt to estimate the fate and transport of organic contaminant must be based on a reasonably accurate knowledge of HOC solubility. However, the measurement of aqueous solubility of HOC is very difficult. In many instances, reported data are contradictory. In fact, apparent solubility (caused by colloids or emulsions) rather than real solubility that accounts for this conflicting.

The common method to prepare saturated solutions usually involved adding an excess of solute to water and mechanically stirring the mixture for at least 24 hours. This method leads to the phenomenon of "accommodation" rather than solubility if these solutions were not allowed to settle comparatively long times (Peake and Hodgson, 1966, Peake and Hodgson, 
1967). The wide distribution of measured solubilities for the various hydrocarbons suggests experimental procedure controls solubility. The more hydrophobic the compound is, the easier for colloids or emulsions to form. Neither filtering nor centrifuging is entirely satisfactory methods of overcoming these colloidal solute particles. Peake and Hodgson (1966 and 1967) concluded that the factors which affect real solubility included hydrocarbon supply, shaking period, setting period, and filter pore-size. In order to eliminate this accommodation, some researcher designed the new methods, for example, using generator column in preparing saturated solution (May et al., 1978, Velapoldi, 1983 and Billington, 1988); others critically reviewed the available data (Mackay, 1981); meanwhile, several models were developed to predict aqueous solubilities of hydrocarbons (Leinonen et al., 1971, Yalkowsky et al., 1979 and 1983, Nirmalakhandan and Speece, 1989, and Ruelle et al., 1993).

\subsection{Physical and Chemical Properties of Studied Compounds}

Seven chlorobenzenes were studied in this research. Trichloroethene was used as co-solute. The physical and chemical properties of these compounds are listed in Table 2.1. It should be noted that 1,4-dichlorobenzene, 1,2,3trichlorobenzene, and 1,3,5-trichlorobenzene are solids at $25^{\circ} \mathrm{C}$. 
Table 2.1. Physical and Chemical Properties of Studied Compounds

\begin{tabular}{lllll}
\hline Compound & MW & $\begin{array}{l}\text { Density }\left(20^{\circ} \mathrm{C}\right) \\
\left(\mathrm{g} / \mathrm{cm}^{3}\right)\end{array}$ & $\begin{array}{l}\text { M.P. } \\
\left({ }^{\circ} \mathrm{C}\right)\end{array}$ & $\begin{array}{l}\text { B.P. } \\
\left({ }^{\circ} \mathrm{C}\right)\end{array}$ \\
\hline Chlorobenzene & 112.56 & $1.107^{1}$ & -45.6 & 132 \\
1,2-Dichlorobenzene & 147.01 & $1.306^{1}$ & -17.0 & 180 \\
1,3-Dichlorobenzene & 147.01 & $1.2884^{1}$ & -24.7 & 173 \\
1,4-Dichlorobenzene & 147.01 & $1.241^{1}$ & 53.1 & 174 \\
1,2,3-Trichlorobenzene & 181.45 & $1.69^{1}$ & 53 & 218 \\
1,2,4-Trichlorobenzene & 181.45 & $1.5707^{1}$ & 16.95 & 213.5 \\
1,3,5-Trichlorobenzene & 181.45 & $1.3865^{2}$ & 63 & 208 \\
Trichloroethene & 131.40 & $1.464^{3}$ & -73 & 87 \\
\hline
\end{tabular}

1 From D. Mackay et al., 1992

2 At $64^{\circ} \mathrm{C}$

3 From manufacture 


\section{Chapter 3}

\section{METHODS AND MATERIALS}

Batch experiments were used to determine both the solubilities of pure chlorobenzenes and effects of TCE on the solubilities of these chlorobenzenes.

Upon reviewing the literature on the solubility of chlorobenzenes, we discovered that solubilities for same compound ranged over two orders of magnitude. The preliminary experiments discovered that these problems resulted from (1) inadequate time to reach equilibrium, and (2) inadequate time to allow emulsions and colloids formed during mixing to settle out. Thus, the most challenging work in this research was to prepare equilibrium aqueous solutions of chlorobenzenes.

\subsection{Chemicals and Apparatus}

All the chlorobenzenes used were of highest grade commercially available and obtained from Aldrich Chemicals. The stated purity or grade is given in parentheses. Monochlorobenzene (99.99\%); 1,2-Dichlorobenzene (99\%); 1,3-Dichlorobenzene (98\%); 1,4-Dichlorobenzene (99+\%); 1,2,3-

Trichlorobenzene (99\%); 1,2,4-Trichlorobenzene $\quad(99+\%) ; \quad 1,3,5-$ Trichlorobenzene (99\%). Trichloroethene $(99+\%)$ and Carbon disulfide $(99.9+\%)$, used to prepare standard solutions of monochlorobenzene, were also from Aldrich Chemical. Hexane (99.9\%), used in extractions and preparing standard solutions, was purchased from Fisher Scientific. The 
water used in this study was collected from Milli-Q system and then distilled from a potassium permanganate water solution.

Two gas chromatographs (GC) were used to measure concentrations of hydrophobic organic compounds. One was a Hewlett Packard Model 5890A fitted with an electron capture detector (ECD). Chromatograms were recorded with a Hewlett Packard Model 3394 integrator. This GC was equipped with an automatic sampler, Hewlett Packard Model 7673 GC/SFC. A $5 \mathrm{~m} \times 0.32 \mathrm{~mm}$, RSL $300 \mathrm{BP}$, capillary column was used in the experiments. Nitrogen was chosen to be carrier gas, and the gas line was equipped with moisture and oxygen traps. This GC was used to analyze all the chlorobenzenes but monochlorobenzene. Oven temperature was adjusted from 150 to $290^{\circ} \mathrm{C}$ depending on the melting point of chlorobenzene, and injector temperature was correspondingly controlled from 180 to $300^{\circ} \mathrm{C}$, and detector temperature maintained at $350^{\circ} \mathrm{C}$. Column head pressure was 70 psi. A second GC, fitted with flame ionization detector (FID), a Varian Model 3700 equipped with a reporting integrator, Hewlett Packard Model 3390A, was used for monochlorobenzene and TCE. The column used was BONDED FSOT, RSL $-150,30 \mathrm{~m} \times 0.53 \mathrm{~mm}, 1.2 \mu \mathrm{m}$, MAOT $330^{\circ} \mathrm{C}$, with polydimethyl- siloxane as stationary phase. Nitrogen and hydrogen, ultra high purity grade, and air, zero grade, were used on this GC. Oven temperature was set around $110^{\circ} \mathrm{C}$, injector temperature, $200^{\circ} \mathrm{C}$, and detector temperature maintained at $220^{\circ} \mathrm{C}$. Column head pressure was about 35 psi. 


\subsection{Batch Experiments}

All the batch experiments were conducted at temperature of $25^{\circ} \mathrm{C}$. Since the organic to water ratio is very low $(0.003 \%-0.3 \%)$ in this study, no organic solvent was used to clear bottles for batch experiments. The bottles were first soaked in soap water, then shaken one by one and rinsed with Milli-Q water. Then, these bottles were placed in nitric acid solution (acid (70\%) to water ratio is 1 to 3) for 24 hours, rinsed again with Milli-Q water, dried in oven $\left(100^{\circ} \mathrm{C}\right)$ for 24 hours. Batch experiments were conducted for solubilities of both pure compound and the co-solute effects.

\subsubsection{Aqueous Solubility of Pure Compounds}

The $63 \mathrm{ml}$ bottles with air-free glass stoppers were first chosen to prepare aqueous solution for the solubility measurements. Later the amber bottles with open caps and teflon septa are also used owing to their ease of use. The results were same from using either of these bottles.

\subsubsection{Experimental Set-up}

A bottle was filled with distilled water and no headspace was allowed. A known mass of chlorobenzene, less than 2.5 times of its expected solubility, was added to the bottom of the bottle by syringe for liquid chlorobenzenes to make sure no solute is lost when closing the cap. Even though the densities of liquid chlorobenzenes at $25^{\circ} \mathrm{C}(1.11-1.57 \mathrm{~g} / \mathrm{cm})$ are greater than that of water, undissolved chlorobenzenes were often present on the water surface. A known amount of solid (17 mg - $46 \mathrm{mg}$ ) was added in the case of solid chlorobenzenes. The bottle was sealed with Parafilm, and mixed at least one 
week in the dark on a rotisserie, a slowly rotating mixer. Then, the solution was settled in the dark inside a controlled temperature bath $\left(25 \pm 0.1^{\circ} \mathrm{C}\right)$ for at least 30 days. The mixture became two phase system with small organic drops on the bottom of bottle. Aqueous samples were taken from the center of the bottle by syringe. All solutions were made in duplicate.

\subsubsection{Standard Calibration Curve}

Standard calibration curves for chlorobenzene and TCE were prepared the same day as the solutions were analyzed. Standard solutions of dichlorobenzenes and trichlorobenzenes were prepared in hexane in concentration of part per million (ppm). These standard solutions were then injected into a GC with ECD. At least 5 standards of known concentration were used for the calibration curve. Standard calibration curves were determined by linear regressions of the peak heights (or peak areas) versus the concentration of standard solutions. For monochlorobenzene, standard solutions were prepared in carbon disulfide for use with the FID detector. Aqueous solutions saturated with TCE were prepared at least 20 days prior to the day of the measurement. A series of TCE standards were obtained by diluting saturated TCE solution on the day of measurements. The standard solution was injected at least 5 times for each concentration and the average was used for the linear regression.

\subsubsection{Sample Analysis}

Samples were obtained by inserting a hypodermic needle into the middle of bottle, known volume aqueous solution $(0.5-0.9 \mathrm{ml})$ then quickly (to 
minimize evaporative losses) placed into a known volume of hexane (1.2 $1.8 \mathrm{ml}$ ) in teflon lined screw-capped glass bottle, shaking and leaving it stand undisturbed for 20 minutes. Then, the organic phase was removed into a GC vial for GC analysis. The equilibrium solution in each bottle was sampled in duplicate. The solubility of a chlorobenzene, in ppm, was determined by using the peak height of a compound from intergator and the ratio of aqueous solution to hexane. The hexane extraction was proved to be effective. After the first extraction, the organic phase was moved away, and the second extraction was done by putting pure hexane into the old aqueous solution. The ratio of the first extraction to the second extraction (in ppm) is higher than 99.9 percent. For monochlorobenzene, aqueous solubility was measured by direct injection of monochlorobenzene-saturated water into GC equipped with FID. Each sample was injected at least three times. If the difference among the triplicate was greater than $10 \%$, additional samples from equilibrium solution were analyzed. A minimum of 6 values was used to calculate a mean and standard deviation for each concentration.

\subsubsection{Aqueous Solubilities of Mixtures}

The methods were similar to those used for measuring the solubility of pure compounds. For the mixture, the organic phase was too small to be analyzed by the GC because only a slight excess of solute used in the experiments. The volatility of TCE posed some problems. With using open-cap with teflon septa bottle, the TCE was absorbed to teflon surface; if a glass-stopper was used, TCE escaped from water solution when the stopper was removed to take samples. Therefore, for each batch experiment, TCE 
blank solution was prepared at the same time when preparing solution of a mixture of TCE and chlorobenzene. Any losses in the blank was assumed to occur in each of the sample bottles. Figure 3.1 is a plot of TCE added to the system versus the TCE concentration in the aqueous phase for blank TCE solutions. The losses of TCE was directly proportional to TCE concentration in aqueous phase. Using this plot, we can estimate the losses of TCE for different concentrations. The TCE blank solutions were also used for measuring TCE concentration differences between pure TCE solutions and mixtures of TCE with chlorobenzene. This differences are caused by cosolute effect.

For each experiment, a known mass of chlorobenzene and a known mass of TCE were added simultaneously to the bottle which had been filled with distilled water. The concentrations of TCE ranged from $0 \mathrm{ppm}$ to $3300 \mathrm{ppm}$. Chlorobenzenes added exceeded solubility ranged from 1.4 to 2.5 times their solubility for liquid chlorobenzenes, and 17 to 170 times their solubility for solid chlorobenzenes. The amounts of solutes used to prepare these solutions are given in Table 3.1 for liquid chlorobenzenes and in Tables 4.2 to 4.4 for solid chlorobenzenes. A solid chlorobenzene occurred to be a liquid when the TCE added into a bottle exceeded TCE solubility. 


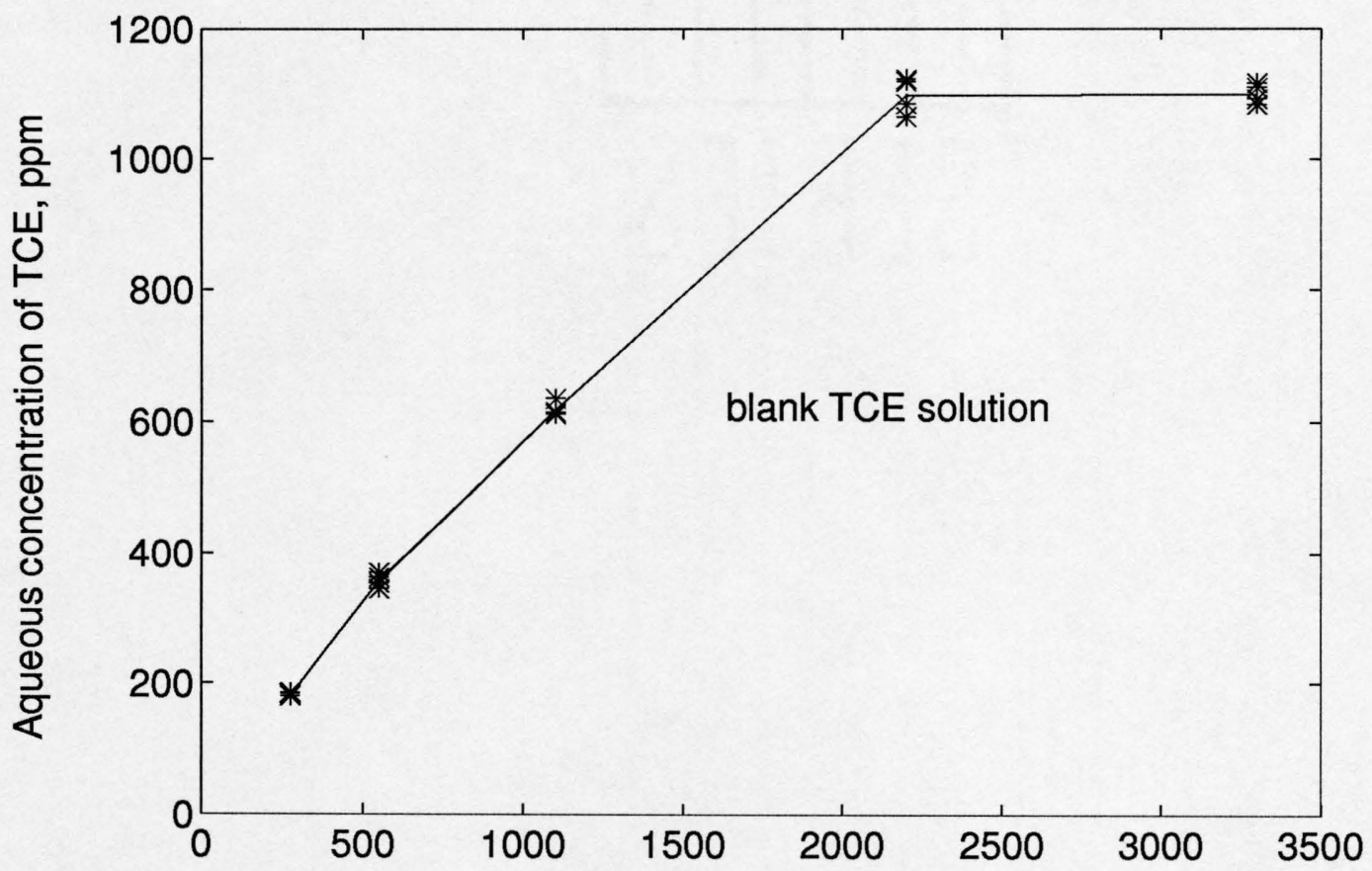

TCE added, ppm

Figure 3.1 The losses of TCE were calculated from TCE blank solutions.

It can be seen from the figure that addding $275,550,1100$, 2200 and 3300 ppm TCE to the solutions, the measured TCE concentrations in aqueous phase are $183,358,619$, 1097 and $1100 \mathrm{ppm}$, respectively. The slope for unsaturated part is about 0.51 . 
Table 3.1. The Amount of Solute Used to Prepare Solutions

\begin{tabular}{lccc}
\hline Compound & $\begin{array}{c}\text { Aqueous } \\
\text { solubility } \\
\text { in pure (ppm) }\end{array}$ & $\begin{array}{c}\text { Amount of } \\
\text { chlorobenzene } \\
\text { added (ppm) }\end{array}$ & $\begin{array}{c}\text { Amount of } \\
\text { TCE }\end{array}$ \\
\hline $\begin{array}{lccc}\text { added (ppm) } \\
\text { 1,2-Dichlorobenzene }\end{array}$ & 127 & 600 & 0 to 3300 \\
1,3-Trichlorobenzene & 115.8 & 200 & 0 to 3300 \\
$1,2,4-$-Trichlorobenzene & 28.6 & 72 & 0 to 3300 \\
\hline
\end{tabular}

Note: The solubility of TCE is $1100 \mathrm{ppm}$ 


\section{Chapter 4}

\section{RESULTS}

Aqueous batch experiments were performed to determine the solubilities of chlorobenzenes in their pure forms and in the mixtures with TCE.

\subsection{Results of Solubilities}

Aqueous solubilities of seven chlorobenzenes were determined at $25^{\circ} \mathrm{C}$, and the results were presented in Table 4.1. These values are in good agreement with those of Mackay and Shiu (1981), the best data available for all the chlorobenzenes. For monochlorobenzene and 1,3-dichlorobenzene, the solubility values are slightly lower than those reported by Mackay and Shiu. It is believed that the solution used in this study was closer to equilibrium state than that of literature.

\subsection{Effect of TCE on the Solubility of Chlorobenzenes}

TCE was introduced as a co-solute for both liquid and solid chlorobenzenes. The effect of TCE on the solubility of liquid chlorobenzenes is different from that of solid chlorobenzenes.

\subsubsection{Effect of TCE on the Solubility of Liquid Chlorobenzenes}

When chlorobenzenes were added in excess of their solubilities, the solutions had two phases, aqueous and organic phases, after equilibrium was reached. Experimental results indicated that increasing concentration of TCE decreased the solubilities of chlorobenzenes. These results are typical 
Table 4.1. The Aqueous Solubilities of 7 Chlorobenzenes at $25^{\circ} \mathrm{C}$

\begin{tabular}{lccc}
\hline Compound & $\begin{array}{c}\text { This Study } \\
(\mathrm{ppm} \pm 1 \mathrm{SD})\end{array}$ & $\begin{array}{c}\text { Literature* } \\
(\mathrm{ppm})\end{array}$ & $\begin{array}{c}\text { Melting Point } \\
\left({ }^{\circ} \mathrm{C}\right)\end{array}$ \\
\hline Chlorobenzene & $432.4 \pm 15$ & $471-503$ & -45.6 \\
1,2-Dichlorobenzene & $127 \pm 4.6$ & $92.7-152$ & -17.0 \\
1,3-Dichlorobenzene & $115.8 \pm 3.9$ & $120-123$ & -24.7 \\
1,4-Dichlorobenzene & $76.7 \pm 3.9$ & $76-90.6$ & 53.1 \\
1,2,3-Trichlorobenzene & $19.3 \pm 0.7$ & $16.6-31.5$ & 53 \\
1,2,4-Trichlorobenzene & $28.6 \pm 2.2$ & $25.0-34.6$ & 16.95 \\
1,3,5-Trichlorobenzene & $9.4 \pm 0.4$ & $6.6-25.1$ & 63 \\
\hline
\end{tabular}

* From Mackay and Shiu, 1981 
for the chlorobenzenes that are liquid at $25^{\circ} \mathrm{C}$. The effects of TCE concentrations on the solubilities of liquid chlorobenzenes were presented in Figures 4.1 to 4.4 for monochlorobenzene, 1,2-dichlorobenzene, 1,3dichlorobenzene and 1,2,4-trichlorobenzene, respectively. From these figures it can be seen that the solubility of chlorobenzene decreases to about a factor of 2 with TCE concentration from 0 to $1000 \mathrm{ppm}$ (below TCE solubility). The amounts of solutes used to prepare these solutions are given in Table 3.1.

\subsubsection{Effect of TCE on the Solubility of Solid Chlorobenzenes}

Results for chlorobenzenes that are solid at $25^{\circ} \mathrm{C}$ are different from those for liquid chlorobenzenes. TCE does not significantly affect their solubilities unless solid chlorobenzenes dissolve in excess pure TCE. The experimental results were tabulated in Tables 4.2 to 4.4 for 1,4-dichlorobenzene, 1,2,3trichlorobenzene and 1,3,5-trichlorobenzene, respectively. If the organic phase was still solid after TCE added to the system, the appearance of crystals was changed from granular to beautiful needle pattern. Therefore, at low concentration of TCE (below $500 \mathrm{ppm}$ ), the presence of TCE may increase the solubilities of solid chlorobenzenes because the surface area was changed in present of TCE. Since we added very small amount of chlorobenzene to prepare the solution in this research, thus, the effect of low concentration TCE on the solubilities of solid chlorobenzenes were not quite clear. However, solubilities of chlorobenzene decreased when TCE concentrations were beyond TCE solubility, especially when solid chlorobenzene completely dissolved in organic TCE phase. 


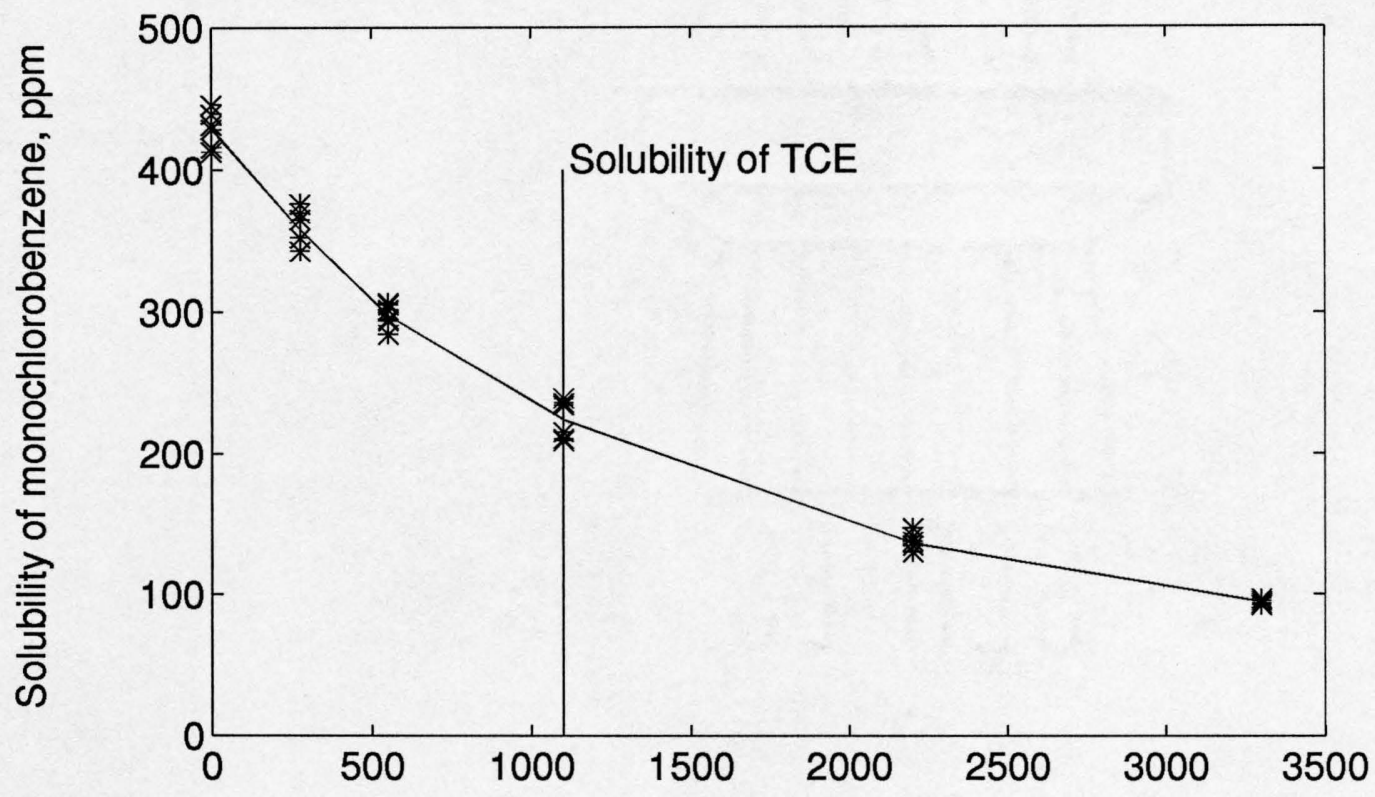

TCE added, ppm

Figure 4.1 Solubilities of monochlorobenzene in the presence of varying amounts of TCE. Concentrations of monochlorobenzene in the system were $600 \mathrm{ppm}$. The solubility for monochlorobenzene is $432 \mathrm{ppm}$. 


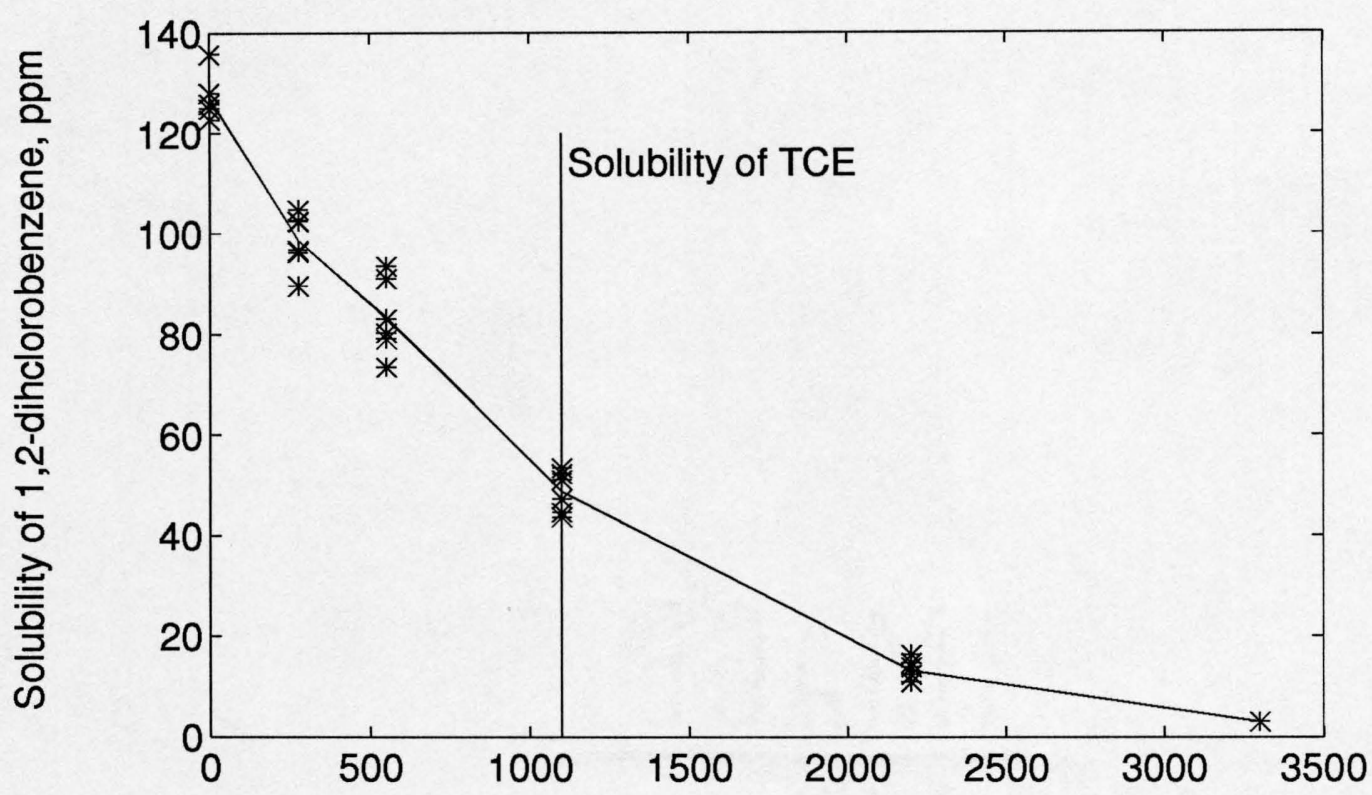

TCE added, ppm

Figure 4.2 Solubilities of 1,2-dichlorobenzene in the presence of varying amounts of TCE. Concentrations of 1,2-dichlorobenzene in the system were $200 \mathrm{ppm}$. The solubility for 1,2 -dichlorobenzene is $127 \mathrm{ppm}$. 


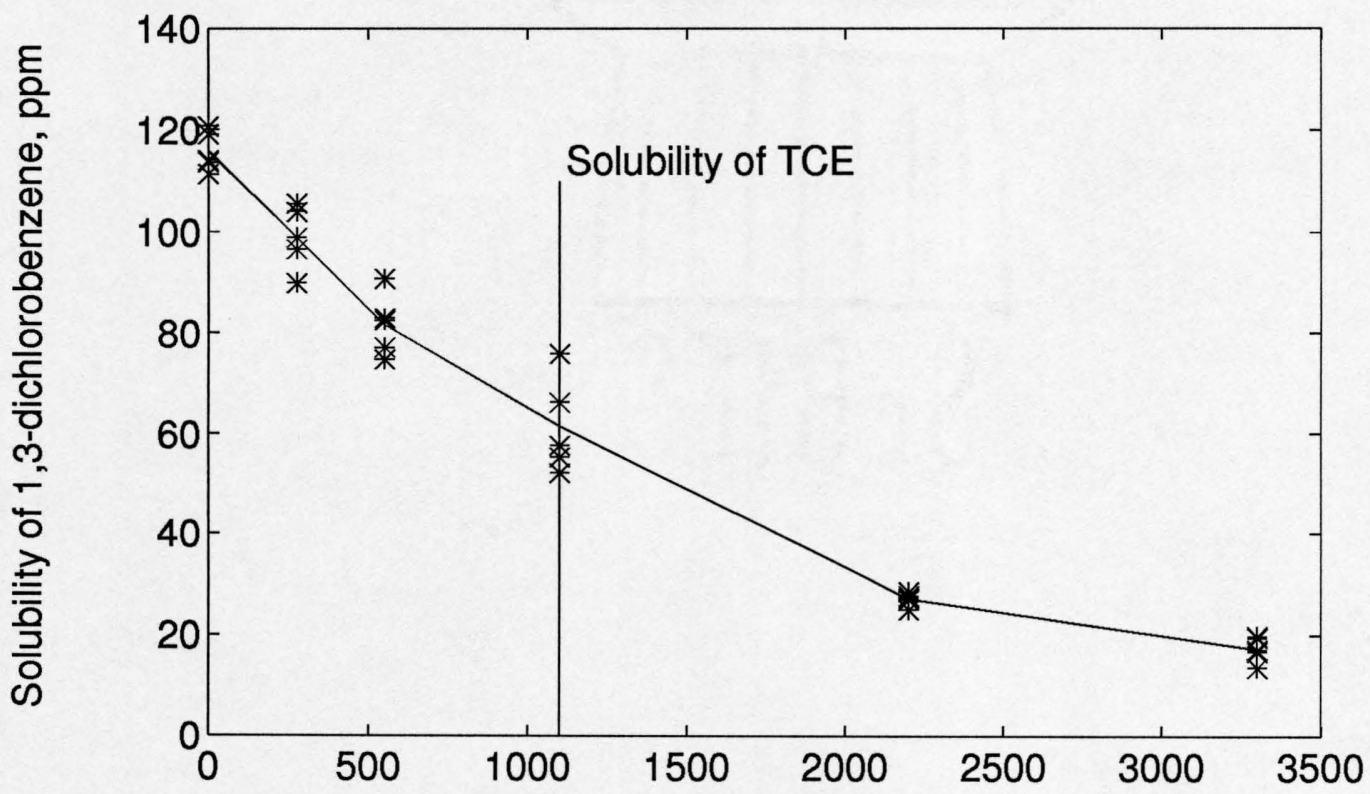

TCE added, ppm

Figure 4.3 Solubilities of 1,3-dichlorobenzenein the presence of varying amounts of TCE. Concentrations of 1,3-dichlorobenzene in the system were $204 \mathrm{ppm}$. The solubility for 1,3-dichlorobenzene is $116 \mathrm{ppm}$. 


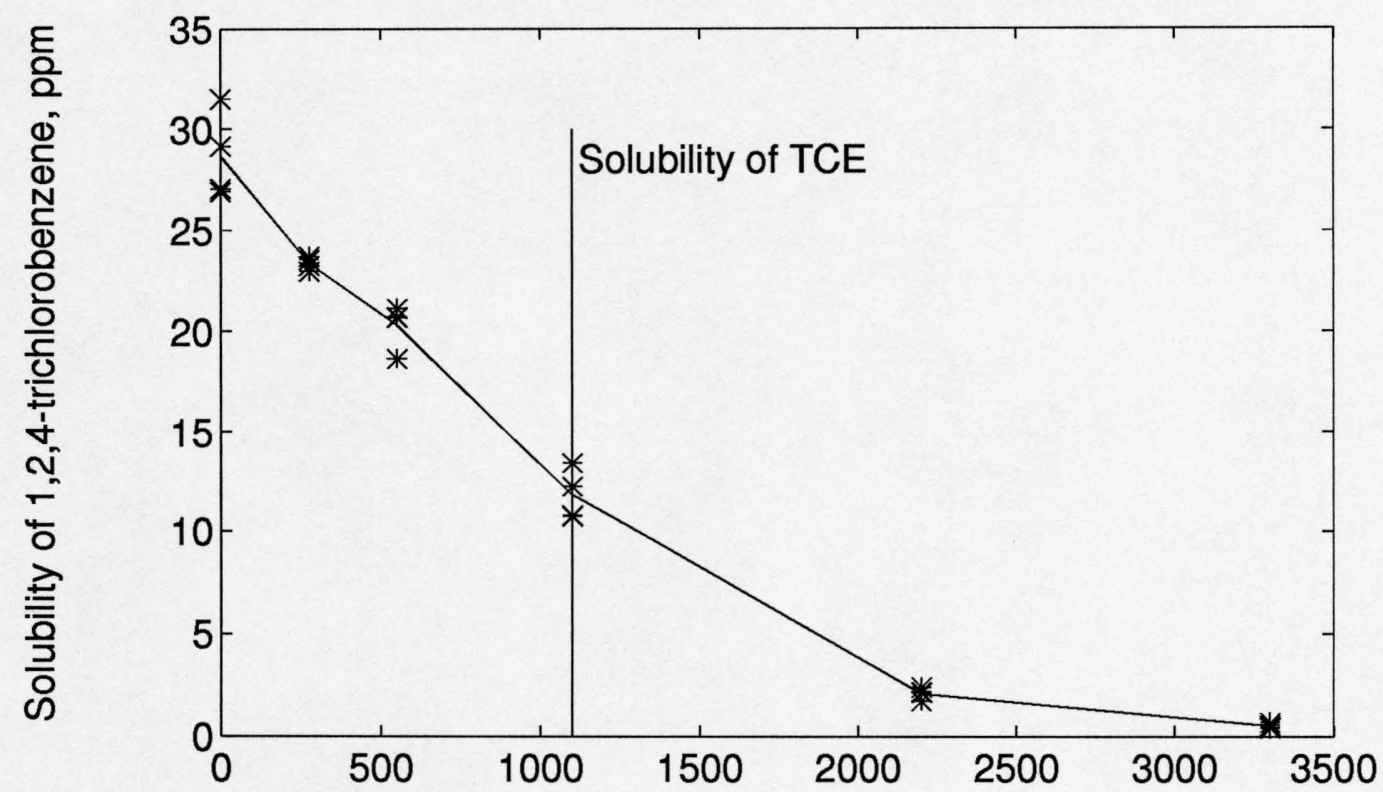

TCE added, ppm

Figure 4.4 Solubilities of 1,2,4-trichlorobenzene in the presence of varying amounts of TCE. Concentrations of 1,2,4-trichlorobenzene in the system were $72 \mathrm{ppm}$. The solubility for $1,2,4$-trichlorobenzene is $28.6 \mathrm{ppm}$. 
Table 4.2. Effect of TCE on the Solubility of 1,4-Dichlorobenzene*

\begin{tabular}{cccc}
\hline TCE & Dichlorobenzene & DCB Solubility & Organic Phase \\
Added $(\mathrm{ppm})$ & Added $(\mathrm{ppm})$ & $(\mathrm{ppm})$ & $\left(\right.$ at $\left.25^{\circ} \mathrm{C}\right)$ \\
\hline 0 & --- & 76.7 & solid \\
345.3 & 180.8 & 77. & solid \\
575.5 & 235.8 & 70.8 & solid \\
920.8 & 408.8 & 73.5 & liqui + solid \\
$1381 * *$ & 512.6 & 66.6 & dissolved in TCE \\
$2072 * *$ & 224.8 & 30.9 & dissolved in TCE \\
$3223 * *$ & 529.9 & &
\end{tabular}


Table 4.3. Effect of TCE on the Solubility of 1,2,3-Trichlorobenzene*

\begin{tabular}{|c|c|c|c|}
\hline $\begin{array}{c}\text { TCE } \\
\text { Added ( ppm ) }\end{array}$ & $\begin{array}{l}\text { Trichlorobenzene } \\
\text { Added ( ppm ) }\end{array}$ & $\begin{array}{l}\text { TCB Solubility } \\
\text { ( ppm ) }\end{array}$ & $\begin{array}{c}\text { Organic Phase } \\
\text { ( at } 25^{\circ} C \text { ) }\end{array}$ \\
\hline 0 & -- & 19.3 & solid \\
\hline 348.6 & 330.2 & 22.0 & solid \\
\hline 581.0 & 436.5 & 21.0 & solid \\
\hline 929.5 & 638.1 & 20.2 & solid \\
\hline $1394 * *$ & 639.7 & 21.9 & solid \\
\hline $2091 * *$ & 331.7 & 16.3 & dissolved in TCE \\
\hline $3253 * *$ & 493.7 & 12.5 & dissolved in TCE \\
\hline 929.5 & 296.8 & 26.9 & solid \\
\hline 929.5 & 465.1 & 22.8 & solid \\
\hline 929.5 & 704.8 & 23.0 & solid \\
\hline 929.5 & 723.8 & 28.5 & solid \\
\hline
\end{tabular}

* Solid at $25^{\circ} \mathrm{C}$

** Above solubility 
Table 4.4. Effect of TCE on the Solubility of 1,3,5-Trichlorobenzene*

\begin{tabular}{cccc}
\hline $\begin{array}{c}\text { TCE } \\
\text { Added }(\mathrm{ppm})\end{array}$ & $\begin{array}{c}\text { Trichlorobenzene } \\
\text { Added }(\mathrm{ppm})\end{array}$ & $\begin{array}{c}\text { TCB Solubility } \\
(\mathrm{ppm})\end{array}$ & $\begin{array}{c}\text { Organic Phase } \\
\left(\text { at } 25^{\circ} \mathrm{C}\right)\end{array}$ \\
\hline 0 & -- & 9.4 & solid \\
345.8 & 488.2 & 7.41 & solid \\
576.4 & 445.7 & 9.8 & solid \\
922.2 & 341.7 & 7.01 & solid \\
$1383 * *$ & 269.3 & 8.38 & solid \\
$2075 * *$ & 352.2 & 5.59 & dissolved in TCE \\
$3228 * *$ & 348.0 & 1.68 & dissolved in TCE \\
922.2 & 340.0 & 8.48 & solid \\
922.2 & 267.7 & 8.79 & solid \\
922.2 & 510.2 & 8.99 & solid \\
922.2 & 381.1 & 8.89 & solid \\
\hline
\end{tabular}

* Solid at $25^{\circ} \mathrm{C}$

** Above solubility 


\subsubsection{Solubility in Mixtures}

While the solubility of liquid chlorobenzene decreases in the presence of TCE, it was observed that the concentration of TCE decreases, too, in the presence of liquid chlorobenzene. It appears the mixtures obey Raoult's Law (equation (14) ). The experimental results were displyed on Figure 4.5. The data demonstrated that if $1100 \mathrm{ppm}$ TCE had added to two separate bottles, the aqueous concentration of TCE was $1003 \mathrm{ppm}$ in the bottle without chlorobenzene, but only $733 \mathrm{ppm}$ in the bottle with $200 \mathrm{ppm} \mathrm{1,2-}$ dichlorobenzene in the system, i.e., $270 \mathrm{ppm}$ TCE partitioned to 1,2-DCB. For low concentration of TCE (below $500 \mathrm{ppm}$ ), the presence of 1,2dichlorobenzene $(200 \mathrm{ppm})$ did not significantly affect the concentrations of TCE.

\subsection{Apparent Solubilities}

\subsubsection{Accommodation and Apparent Solubilities}

Results from the batch experiments indicated that apparent solubilities, resulted from accommodation, strongly depended on the amount of solute that mixed with water. Liquid solutes were accommodated to a greater extent than solid solutes. Settling times of a few weeks sharply reduced the measured accommodation. Figure 4.6 illustrates apparent solubility versus amount of solute added. In Figure 4.6.A, the apparent solubility of 1,2dichlorobenzene $(1,2-\mathrm{DCB})$ is directly proportional to availability of 1,2 DCB and in Figure 4.6.B, the apparent solubility of 1,2,4-trichlorobenzene $(1,2,4-\mathrm{TCB})$ is directly proportional to availability of $1,2,4-\mathrm{TCB}$. It is clear 


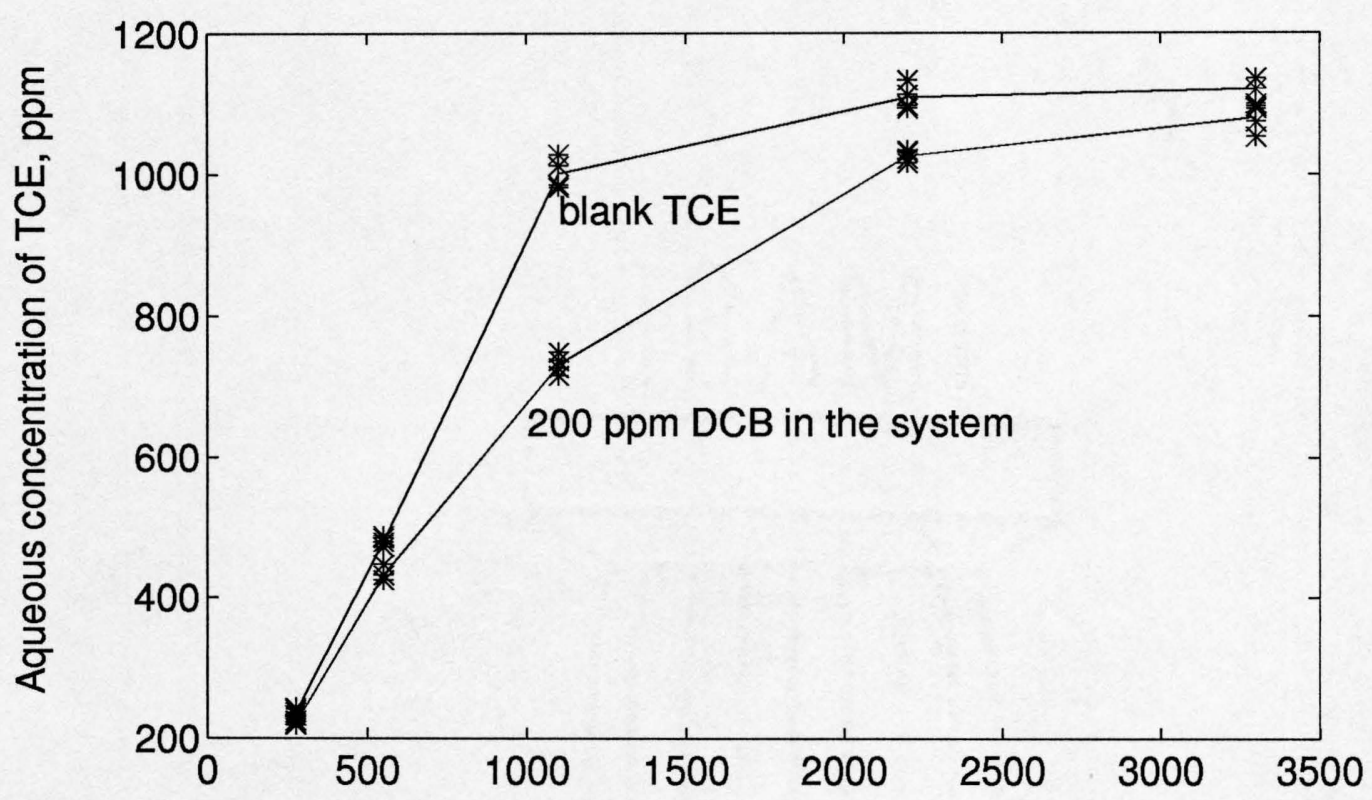

TCE added, ppm

Figure 4.5 For low concentration of TCE (below $500 \mathrm{ppm}$ ), the presence of 1,2-dichlorobenzene (200 ppm) did not significantly affect the concentrations of TCE. However, for concentration near its solubility (1100 ppm), the aqueous concentrations of TCE decrease in the presence of 1,2-dichlorobenzene. 

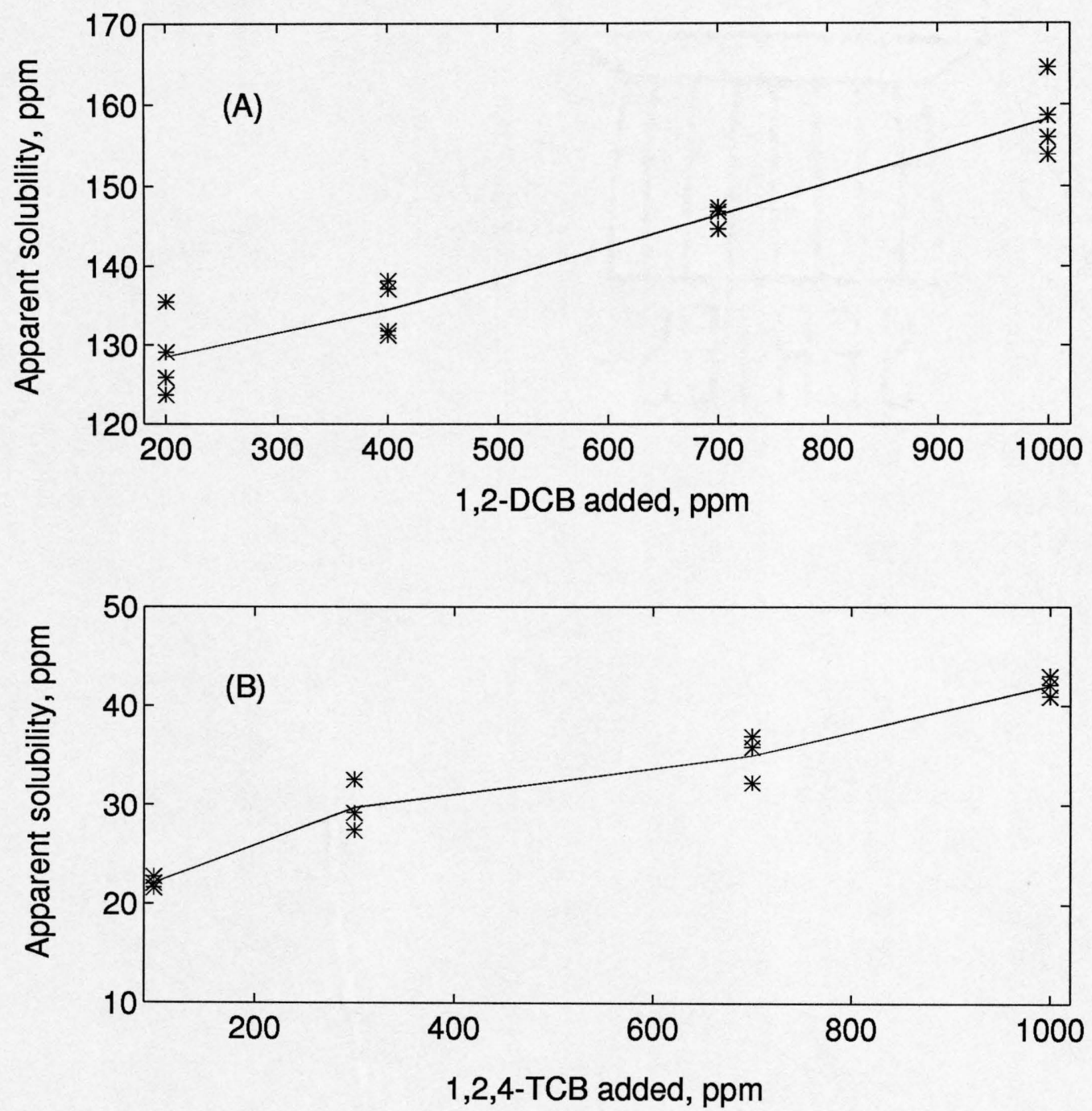

Figure 4.6 Apparent solubilities are directly proportional to solute availability in the system. Settling time is about 12 hours.

(A). Apparent solubilities for 1,2-dichlorobenzene.

(B). Apperent solubilities for 1,2,4-trichlorobenzene 
however that apparent solubilities are higher than real solubility. These solutions were mixed on a rotisserie for seven days, and stood undisturbed for 12 hours.

In order to obtain reliable solubility limits of these compounds, eliminating the effect of colloids became critical important. Centrifugation was attempted to settle down these colloids. However, centrifugation resulted in large escape of dissolved solute from centrifuge tube to the air due to the vacuum formed inside centrifuge, which excesses the speed for solute to be dissolved into water. Centrifugation results were given in Figure 4.7. From top to the bottom, the first line indicates the apparent solubilities of three samples before centrifugation; the second line was concentrations of solutions after 30 minutes at $700 \mathrm{~g}$ centrifugation with capped centrifuge tubes; and the third line was concentrations of solutions obtained from 60 minutes at $1000 \mathrm{~g}$ centrifugation.

\subsubsection{Solubility Determination from Apparent Solubilities}

Solutions needed long period settling time (30 days or more for this research) to minimize accommodation. We found one method that obtains reliable solubility determinations for short settling time. In this method, we determined the solubility from the change in slope of apparent solubility versus amount of chlorobenzene added. From Figure 4.6, it can be seen that apparent solubility is directly proportional to the HOC supply and the slope of curve is approximately a straight line. If there were no accommodation in water solution, this slope should theoretically be horizontal. Furthermore, it 


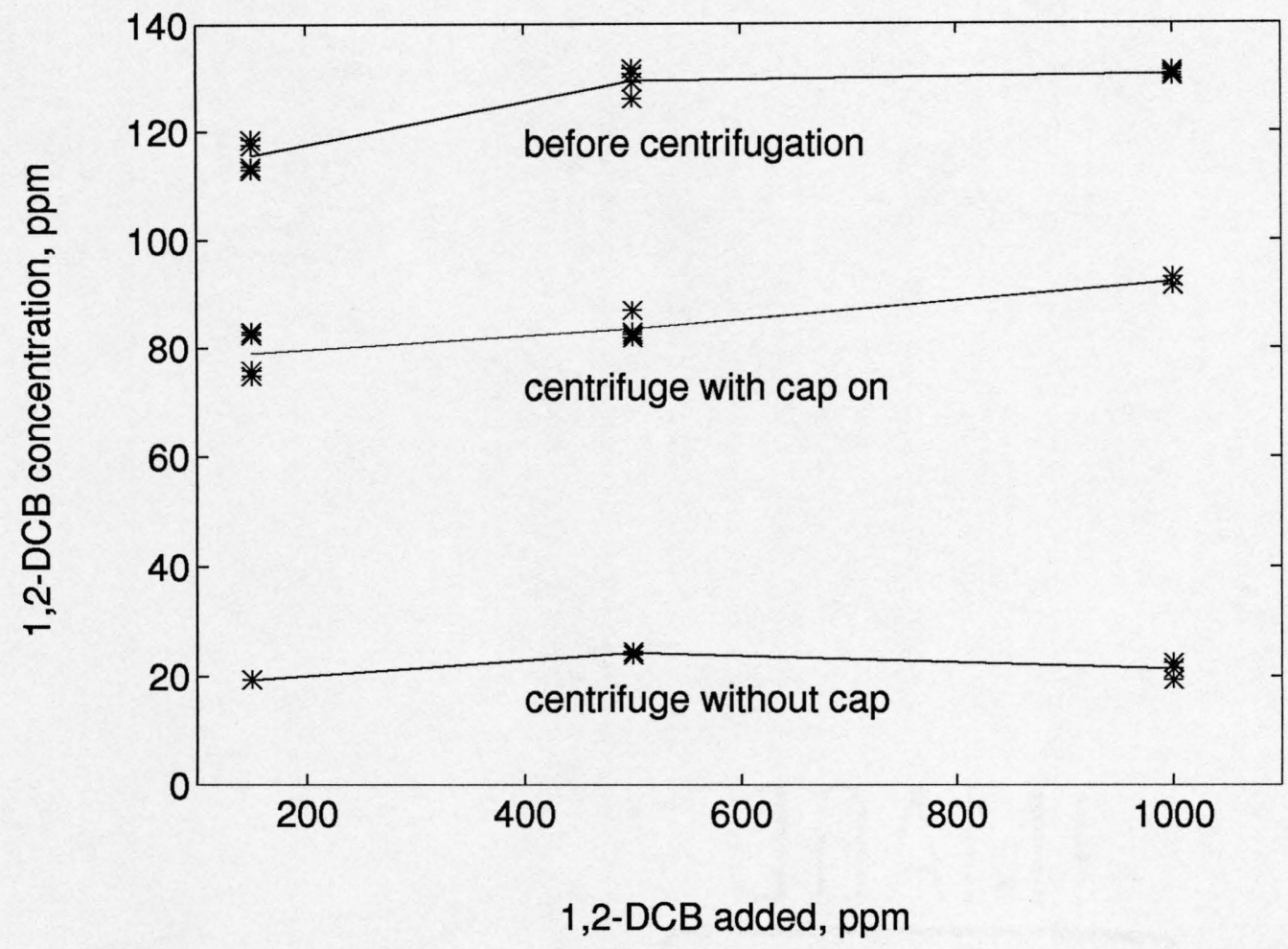

Figure 4.7 Centrifugation resulted in large escape of dissolved 1,2-DCB from centrifuge tube to the air due to the vacuum formed inside the centrifuge.

Centrifuge with cap on: 30 minutes with $700 \mathrm{~g}$.

Centrfuge without cap: 60 minutes with $1000 \mathrm{~g}$. 
was assumed (proved by experiments) when amount of chlorobenzene added was below the solubility, accommodation could be ignored and the slope should be close to one to one ratio, i.e., the concentration of solution is same as the the concentration expected if we ignored the small losses partitioning to the wall of bottle. The method was depicted in Figure 4.8, where actual solubility occurs when the slope change from 1:1 to a lower slope. This method gives solubilities of $125 \mathrm{ppm}$ for 1,2-DCB and $28 \mathrm{ppm}$ for 1,2,4-TCB. This approach is similar to the method of McNally and Grob (1983). They analyzed headspace concentrations of solutions instead of aqueous solutions.

\subsubsection{Apparent Solubilities of Mixtures}

The results show clearly that the solubilities for mixtures have the same trend as those of individual solutes, i.e., apparent solubilities increases with amount of excess solute. The initial results for 1,2-dichlorobenzene (obtained from 1 day settling time or less) for both solubility of pure solute and effects of adding TCE clearly show the effect of forming colloids or emulsions. Figure 4.9 displays apparent solubilities of 1,2-dichlorobenzene with and without TCE. As the amount of added 1,2-dichlorobenzene increased, the apparent solubility of 1,2-dichlorobenzene concomitantly increased. The addition of TCE, as a co-solute, decreased the apparent solubility of 1,2-dichlorobenzene. The Figure 4.10 shows apparent solubility is directly proportional to amount of solute; increasing concentration of TCE decreased the apparent solubilities. The Figure 4.11 indicates that the concentrations of TCE decrease with increasing amount of 1,2dichlorobenzene. For low concentrations of TCE (below $250 \mathrm{ppm}$ ), the 

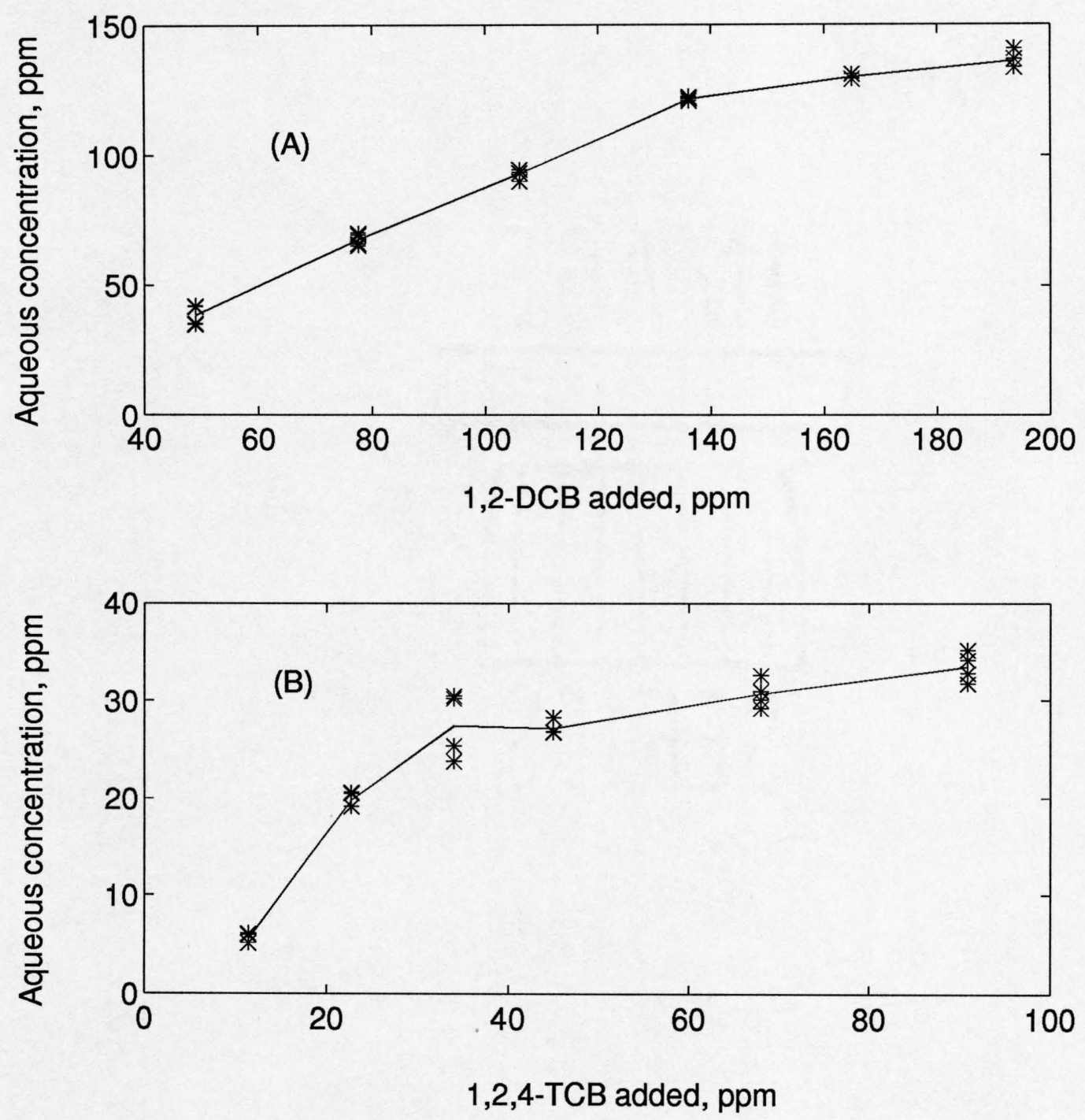

Figure 4.8 Solubility of chlorobenzene as a function of chlorobenzene added to the solution. Actual solubility is determined from the intersection of two lines

(A). Solubility of 1,2-DCB is about $130 \mathrm{ppm}$.

(B). Solubility of $1,2,4-\mathrm{TCB}$ is about $28 \mathrm{ppm}$. 


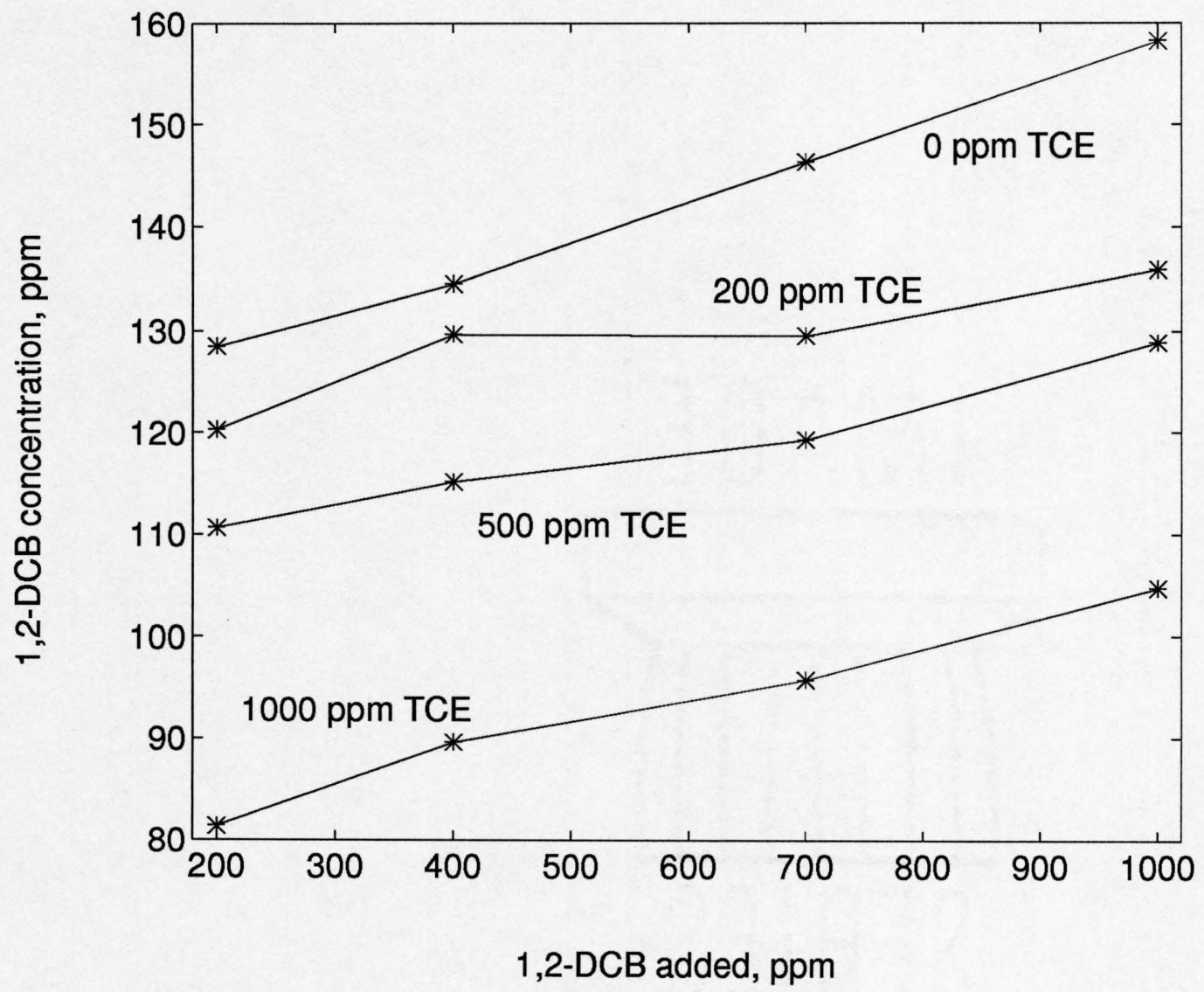

Figure 4.9 The figure shows apparent solubilities of 1,2-dichlorobenzene with and without TCE. The figure indicates that

(1). the apparent solubility is directly proportional to amount of solute.

( 2 ). increasing concentration of TCE decreases the apparent solubility. 


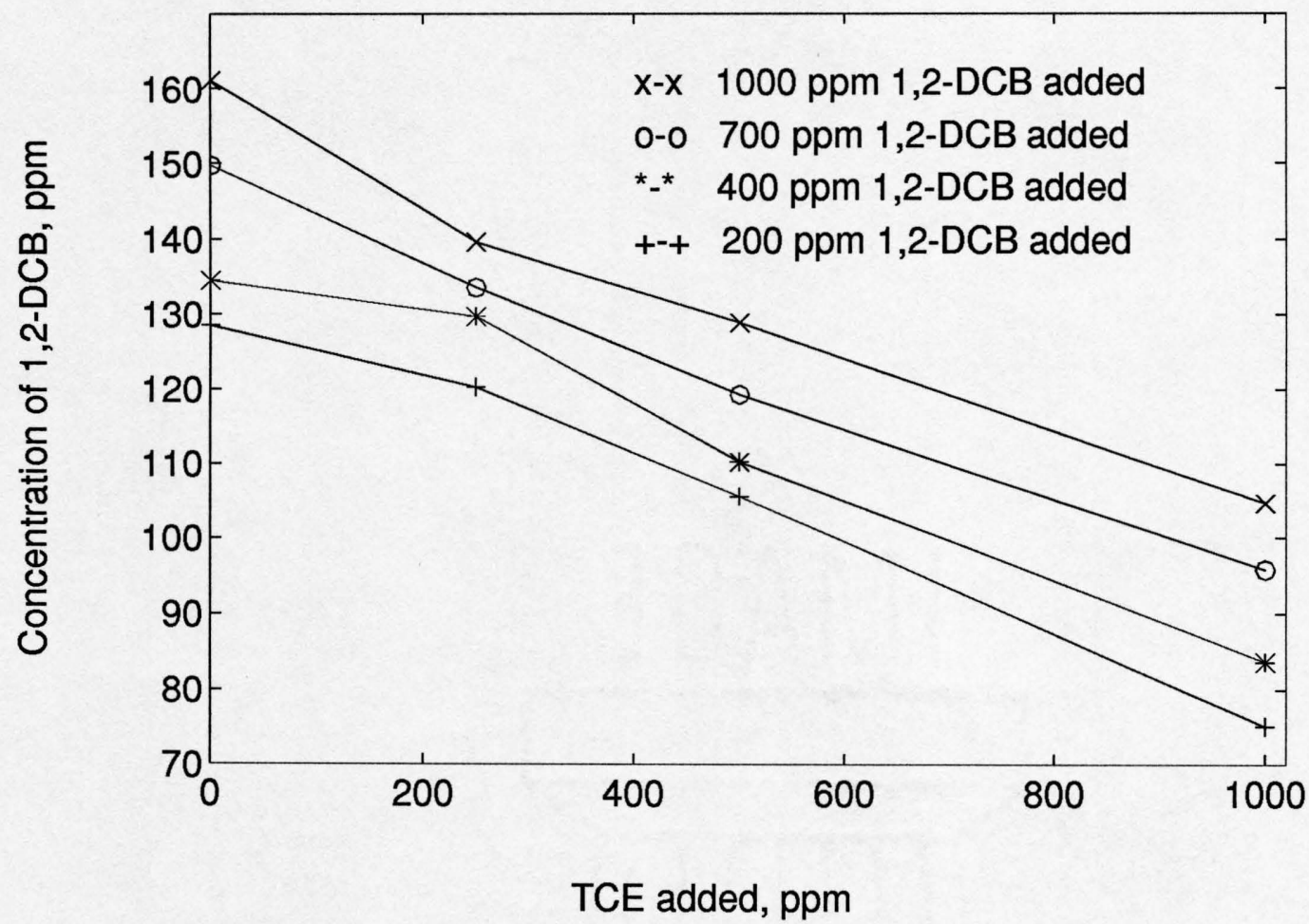

Figure 4.10 The figure shows apparent solubility of 1,2-dichlorobenzene is inverssly proportional to TCE concentration and increases with increasing amount of 1,2-dichlorobenzene. 


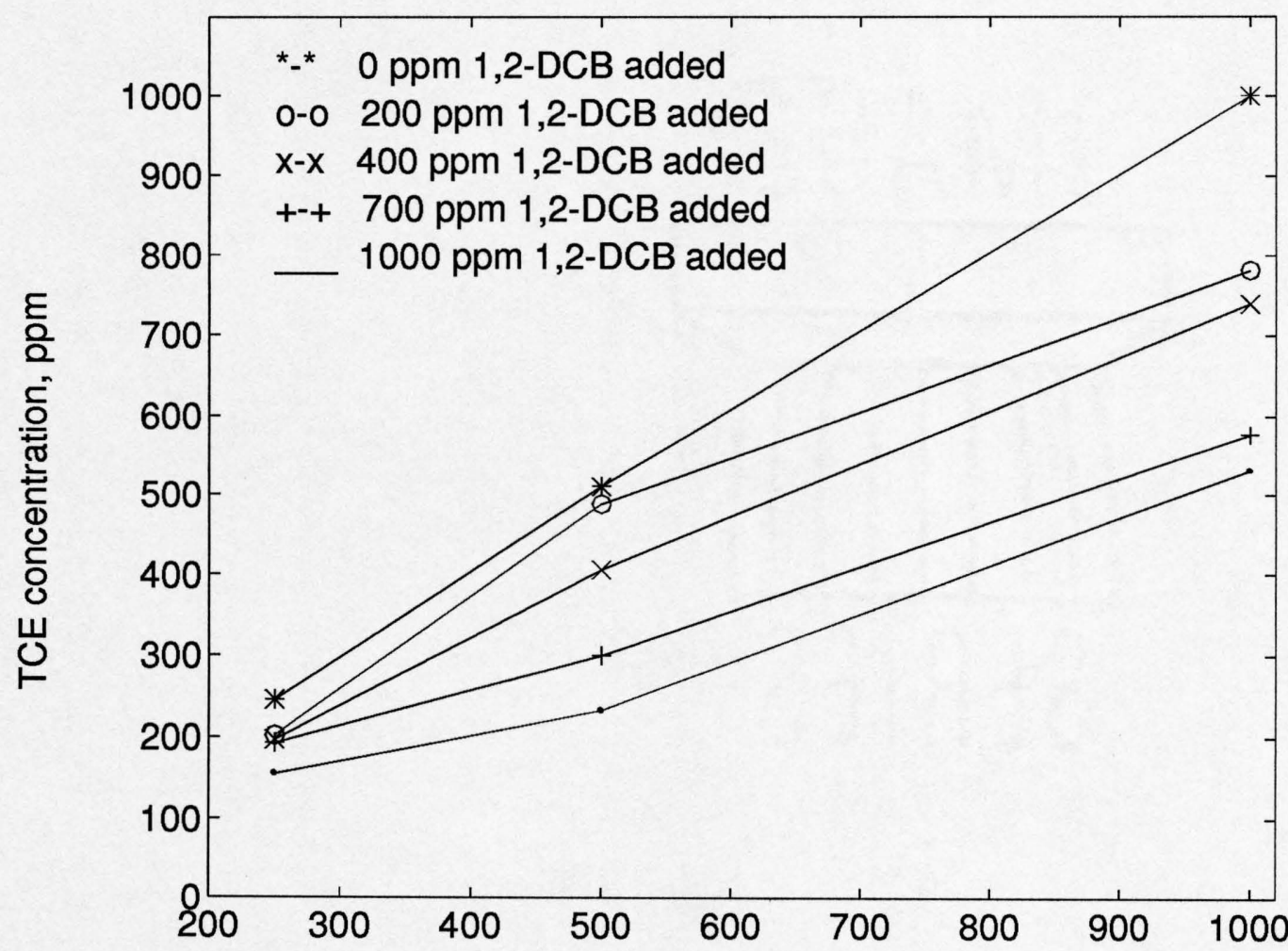

TCE added, ppm

Figure 4.11 The figure shows concentrations of TCE with and without 1,2-dichlorobenzene in the system. The figure indicates that the concentrations of TCE decrease with increasing amount of 1,2-dichlorobenzene. 
concentrations of TCE were not significantly affected in the presence of 1,2dichlorobenzene (see Figure 4.12). However, for concentrations near its solubility ( $1100 \mathrm{ppm}$ ), the aqueous concentrations of TCE decrease with increasing the concentrations of 1,2-dichlorobenzene. 


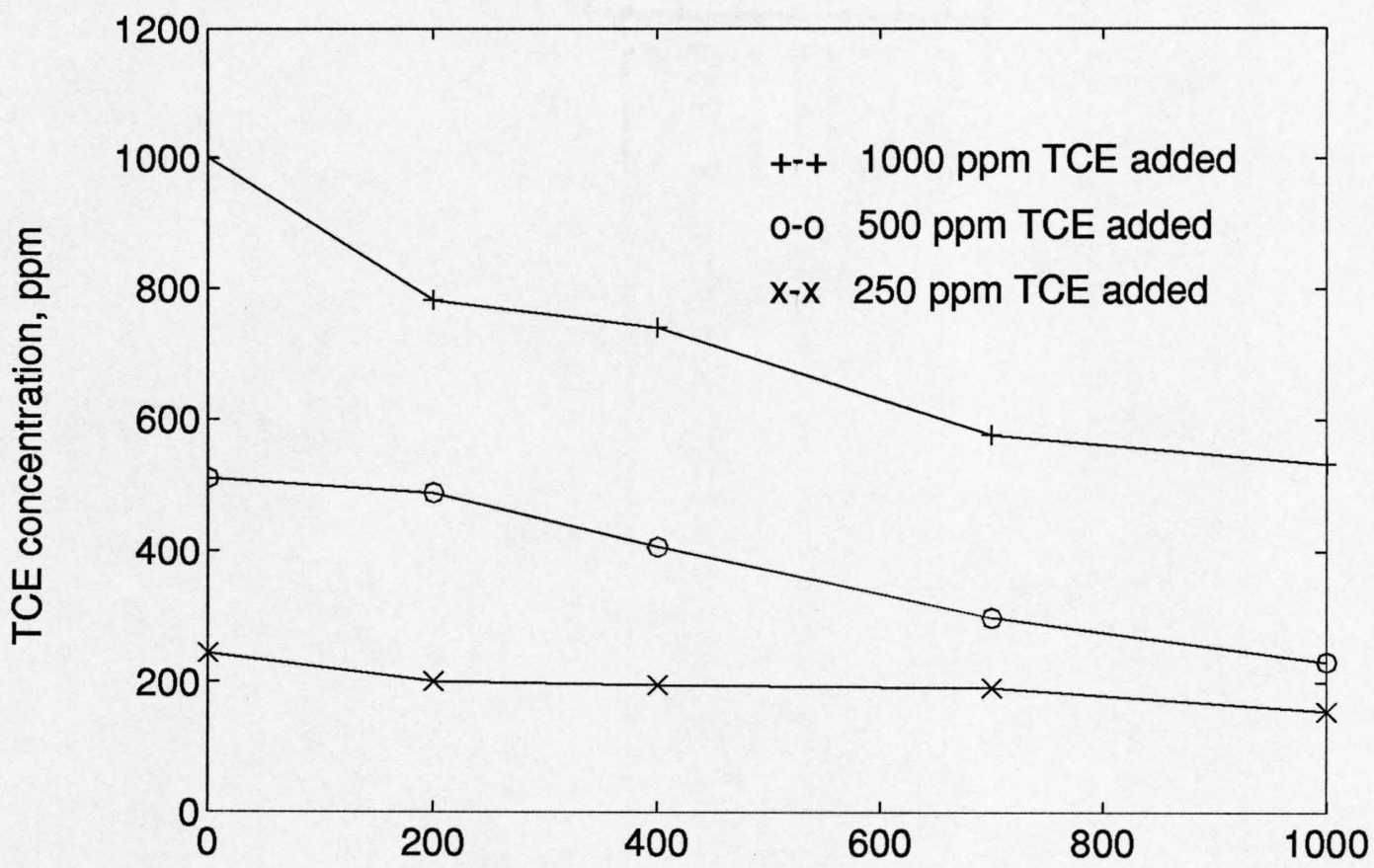

1,2-DCB added, ppm

Figure 4.12 For low concentrations of TCE (250 ppm), concentrations Of TCE were not significantly affected in the presence of 1,2-dichlorobenzene which ranged from $0 \mathrm{ppm}$ to $1000 \mathrm{ppm}$.

For concentration near its solubility $(1100 \mathrm{ppm})$, the aqueous concentrations of TCE decrease with increasing the concentration of 1,3-dichlorobenzene. 


\section{Chapter 5}

\section{DISCUSSION}

\subsection{Error Analysis}

The major sources of experimental error are believed to be as follows: (1) it was possible for colloids of chlorobenzene to enter the syringe and to be introduced to extraction bottles, as a result of disturbing the solution when withdrawing samples from equilibration bottles; (2) the estimate losses of TCE, it is inevitable for TCE to evaporate due to long time settling and extracting manipulation; (3) measurement errors due to the small amount of solute (chlorobenzene) required to prepare standard stock solutions. (e.g., to make $1000 \mathrm{ppm}$ stock solution in a $100 \mathrm{ml}$ flask of hexane, only $66 \mathrm{mg}$ solute is needed); and (4) analytical errors in the GC analysis. Analytical GC errors occurred routinely, peak areas or peak heights from the intergrator were different for different injections from the same vial. These error sources were similar to those of Leinonen and Mackay (1973).

Although some experimental data contained errors up to 7.7 percent, it is obvious that the effects of TCE on the solubilities of chlorobenzenes are significant. For solubility experiments of hydrophobic organic compounds, it is generally believed to be acceptable results for errors below $10 \%$ (Yalkowsky, 1191). 


\subsection{Equilibrium Model}

William (1992) indicated that composition of the nonpolar phase strongly influences the solute concentrations in polar phase, suggesting that Raoult's law is applicable to complex mixtures. The experimental results from this study show the same trend, thus a model similar to Raoult's law for co-solute effect, equation (13) for liquid mixture and equation (19) for solid mixture, was used to analyze our experimental data.

\subsubsection{Mixtures of Liquid Chlorobenzene and TCE}

The decrease in solubility of chlorobenzene by presence of co-solute can explained by a model presented by Banerjee (1984). In the co-solute system, the organic phase is not a pure phase, but a mixture of chlorobenzene and TCE. As the mole fraction of TCE increases (i.e., when more TCE is added to the system), there is a concomitant decrease in the mole fraction of chlorobenzene. The expected behavior can be predicted by equation (13), $s_{i} / S_{i}=\left(x_{i}\right)_{o}$.

Since the volume of the organic phase in each bottle in our experiments was very small, the direct measurements for organic phase were impossible. Thus, the mole fraction of organic phase was calculated from the measured aqueous concentration and the total solutes added to the system. Our experiments results revealed that the losses of TCE is not only due to volatility but also to teflon surface. Losses of TCE were accounted for all the calculations. Figures 5.1 to 5.4 were applications of equation (13) to our data for (A) monochlorobenzene, (B) 1,2-dichlorobenzene, (C) 1,3- 


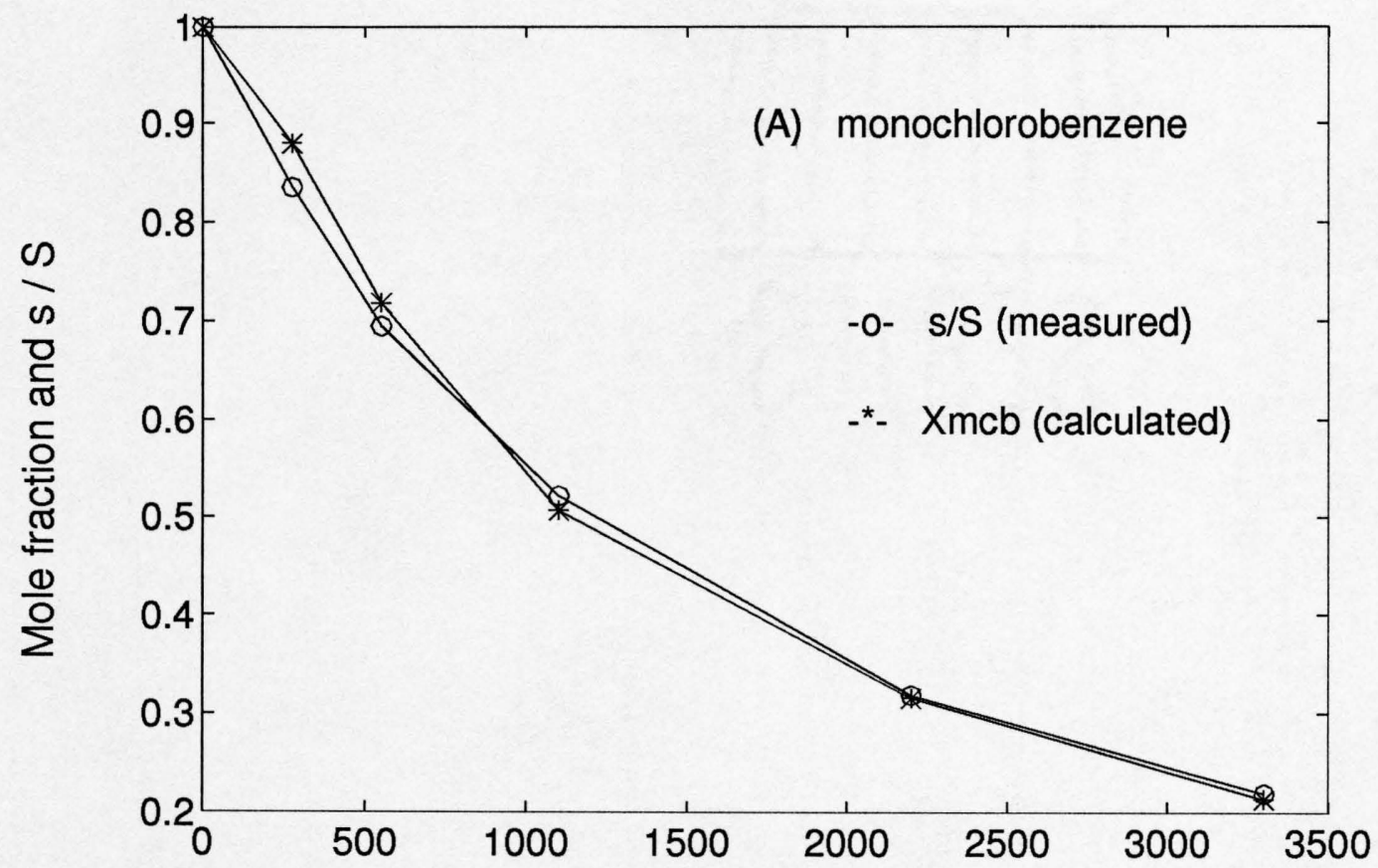

TCE added, ppm

Figure 5.1 The figure shows result of application of equation (13), i. e, $s_{i} / s_{i}=\left(x_{i}\right)_{0}$ for monochlorobenzene. 


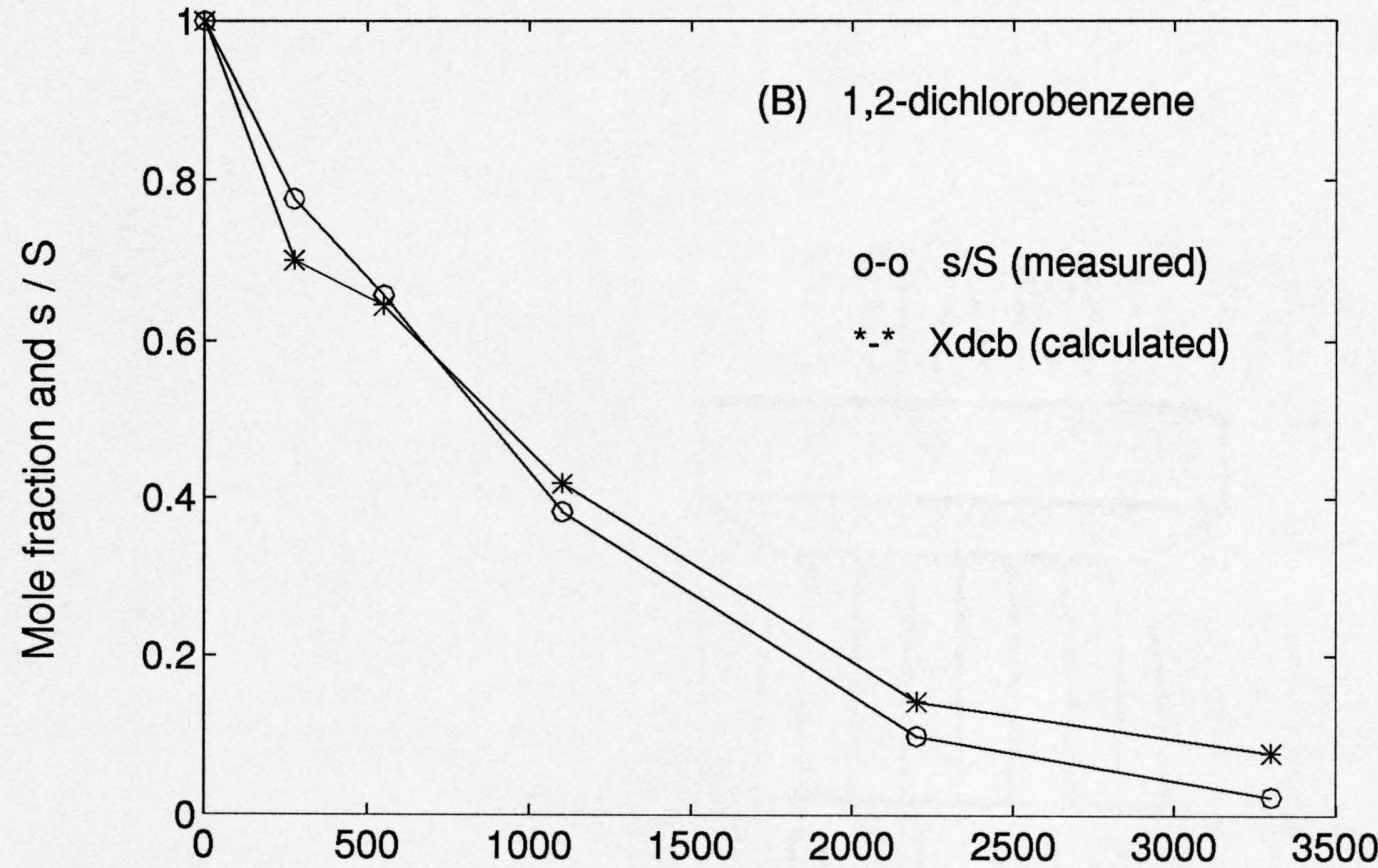

TCE added, ppm

Figure 5.2 The figure shows result of application of equation (13), i. e, $s_{i} / s_{i}=\left(x_{i}\right)_{0}$ for 1,2-dichlorobenzene. 


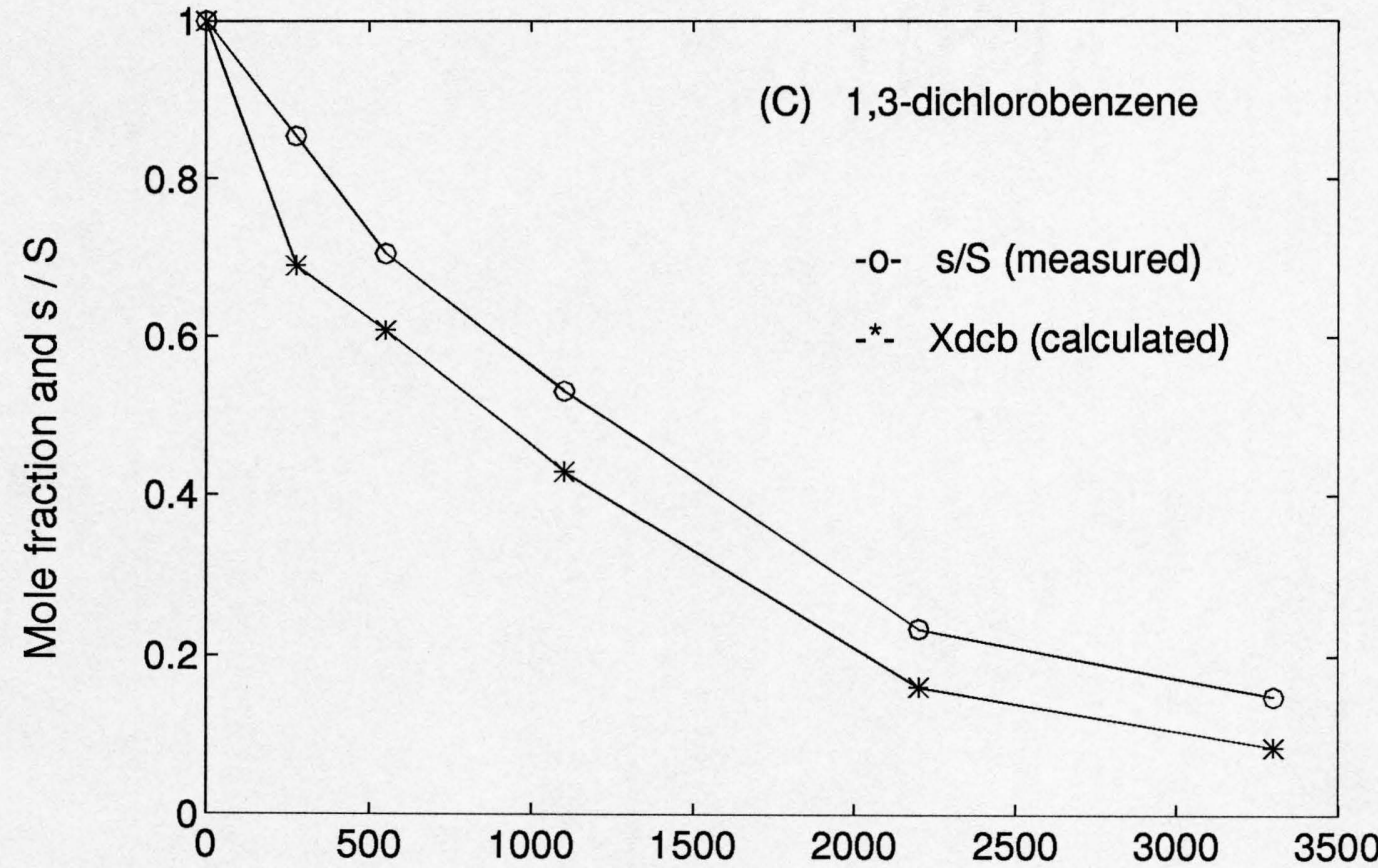

TCE added, ppm

Figure 5.3 The figure shows result of application of equation (13), i. e, $s_{i} / s_{i}=\left(x_{i}\right)_{0}$ for 1,3-dichchlorobenzene. 


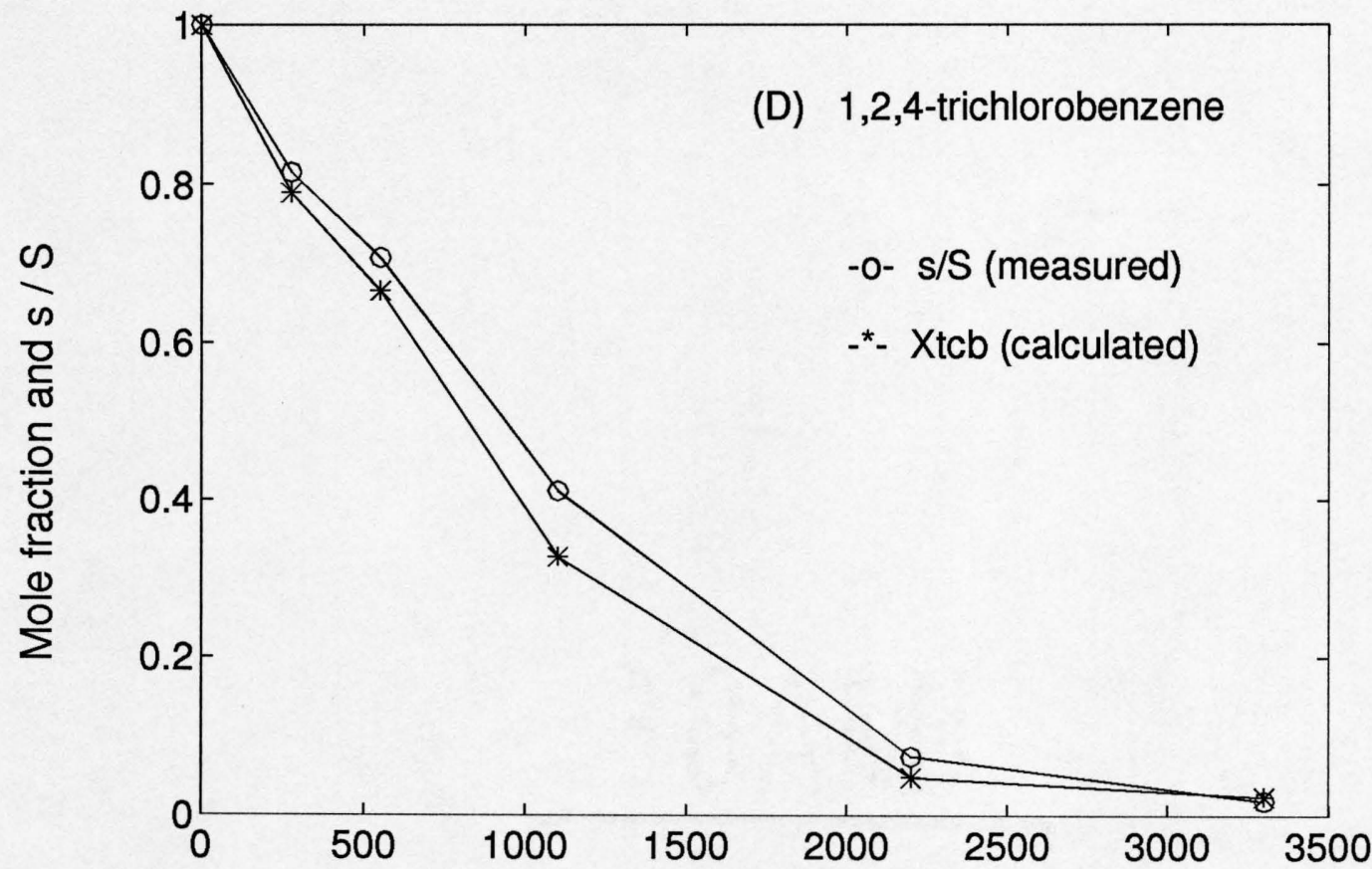

TCE added, ppm

Figure 5.4 The figure shows result of application of equation (13), i. e, $s_{i} / s_{i}=\left(x_{i}\right)_{0}$ for 1,2,4-trichlorobenzene. 
dichlorobenzene and (D) 1,2,4-trichlorobenzene. The calculations for these figures are listed in Tables 5.1 to 5.4. The fits of model were generally good except the fit for 1,3-dichlorobenzene, where the value of $s_{i} / S_{i}$ was higher than that of $X_{d c b}$, i.e., $\left(x_{i}\right)_{o}$. The results suggested that the mixtures of TCE and chlorobenzene were close to being ideal (and only small deviations for 1,3-dichlorobenzene). It is very encouraging to know that these results are in satisfactory agreement with those of Leinonen and Mackay (1973), Tewari et al. (1982), Banerjee (1984), Sugatt et al. (1984), Burris and MacIntyre (1985 and 1986), Lane and Loehr (1992) and Lee et al. (1992). All these researchers measured the solubilities of hydrophobic mixtures in water and found that equation (13) was generally obeyed. Where deviations occurred they were positive; i.e., the measured concentration, $s_{i} / S_{i}$, exceeded the calculated mole fraction in the organic phase, $\left(x_{i}\right)_{o}$. These deviations were attributed by Leinonen and Mackay (1973) to the activity coefficient of the component in the organic phase being slightly greater than unity and a decrease of organic activity coefficient in the aqueous phase by the presence of the other organic component; their results show that these deviations were not much greater than the experimental uncertainty. Burris and MacIntyre (1986), in disagreement with conclusions of Leinonen and Mackay, determined through "a thermodynamic study of solutions of liquid hydrocarbon mixtures in water" that the presence of hydrocarbon co-solute does not measurably reduce hydrocarbon activity coefficients in the aqueous phase. Burris and MacIntyre (1985) observed that significant deviations from ideality occur when the two components differ structurally. Sugatt et al. 
Table 5.1. Effect of TCE on the Solubilities of Monochlorobenzene

\begin{tabular}{lllllll}
\hline Sample No. & 1 & 2 & 3 & 4 & 5 & 6 \\
\hline $\begin{array}{l}\text { Total MCB added } \\
(\mathrm{ppm})\end{array}$ & 600. & 600. & 600. & 600. & 600. & 600. \\
$\begin{array}{l}\text { Total TCE added } \\
(\mathrm{ppm})\end{array}$ & 0. & 275. & 550. & 1100. & 2200. & 3300 \\
$\begin{array}{l}\text { DCB in aqueous phase } \\
(\mathrm{ppm})\end{array}$ & 432.4 & 361.2 & 300.5 & 225.6 & 137.8 & 95.07 \\
$\begin{array}{l}\text { TCE in aqueous phase } \\
(\mathrm{ppm})\end{array}$ & 0. & 180.5 & 314.6 & 514.2 & 787.8 & 867.0 \\
$\begin{array}{l}\text { Lost of TCE } \\
(\mathrm{ppm})\end{array}$ & 0. & 55.9 & 97.5 & 159.4 & 244.2 & 268.8 \\
$\begin{array}{l}\text { DCB in organic phase } \\
(\mathrm{ppm})\end{array}$ & 167.6 & 238.8 & 299.4 & 374.4 & 462.2 & 504.9 \\
$\begin{array}{l}\text { TCE in organic phase } \\
(\mathrm{ppm})\end{array}$ & 0 & 38.5 & 137.9 & 426.4 & 1168. & 2164. \\
$\begin{array}{l}\text { Mole of DCB } \\
\left(10^{-6}\right)\end{array}$ & 1.489 & 2.121 & 2.660 & 3.326 & 4.106 & 4.486 \\
$\begin{array}{l}\text { Mole of TCE } \\
\left(10^{-6}\right)\end{array}$ & 0. & 0.294 & 1.052 & 3.255 & 8.916 & 16.52 \\
$\begin{array}{l}\text { Xdcb in organic phase } \\
(\text { Mole fraction) }\end{array}$ & 1. & 0.878 & 0.716 & 0.505 & 0.315 & 0.213 \\
\begin{tabular}{l} 
s / of DCB \\
\hline
\end{tabular} & 1. & 0.835 & 0.695 & 0.522 & 0.319 & 0.220 \\
\hline
\end{tabular}


Table 5.2. Effect of TCE on the Solubilities of 1,2-Dichlorobenzene

\begin{tabular}{lllllll}
\hline Sample No. & 1 & 2 & 3 & 4 & 5 & 6 \\
\hline $\begin{array}{l}\text { Total DCB added } \\
(\mathrm{ppm})\end{array}$ & 200. & 200. & 200. & 200. & 200. & 200. \\
$\begin{array}{l}\text { Total TCE added } \\
(\mathrm{ppm})\end{array}$ & 0. & 275. & 550. & 1100. & 2200. & 3300. \\
$\begin{array}{l}\text { DCB in aqueous phase } \\
(\mathrm{ppm})\end{array}$ & 127.1 & 98.7 & 83.5 & 48.7 & 13.2 & 3.1 \\
$\begin{array}{l}\text { TCE in aqueous phase } \\
(\mathrm{ppm})\end{array}$ & 0. & 209. & 436. & 808. & 1063. & 1103. \\
$\begin{array}{l}\text { Lost of TCE } \\
(\mathrm{ppm})\end{array}$ & 0. & 27.2 & 56.7 & 105.0 & 138.3 & 143.4 \\
$\begin{array}{l}\text { DCB in organic phase } \\
(\mathrm{ppm})\end{array}$ & 72.9 & 101.3 & 116.5 & 151.2 & 186.8 & 196.9 \\
$\begin{array}{l}\text { TCE in organic phase } \\
(\mathrm{ppm})\end{array}$ & 0 & 38.6 & 57.2 & 186.8 & 998. & 2053. \\
$\begin{array}{l}\text { Mole of DCB } \\
\left(10^{-6}\right)\end{array}$ & 0.496 & 0.689 & 0.792 & 1.029 & 1.271 & 1.340 \\
$\begin{array}{l}\text { Mole of TCE } \\
\left(10^{-6}\right)\end{array}$ & 0 & 0.2947 & 0.4367 & 1.426 & 7.618 & 15.67 \\
$\begin{array}{l}\text { Xdcb in organic phase } \\
(\text { Mole fraction) }\end{array}$ & 1. & 0.700 & 0.645 & 0.419 & 0.143 & 0.079 \\
\begin{tabular}{l} 
s / S of DCB \\
\hline
\end{tabular} & 1. & 0.777 & 0.657 & 0.384 & 0.104 & 0.024 \\
\hline
\end{tabular}


Table 5.3. Effect of TCE on the Solubilities of 1,3-Dichlorobenzene

\begin{tabular}{lllllll}
\hline Sample No. & 1 & 2 & 3 & 4 & 5 & 6 \\
\hline $\begin{array}{l}\text { Total DCB added } \\
(\mathrm{ppm})\end{array}$ & 204. & 204. & 204. & 204. & 204. & 204. \\
$\begin{array}{l}\text { Total TCE added } \\
(\mathrm{ppm})\end{array}$ & 0. & 275. & 550. & 1100. & 2200. & 3300. \\
$\begin{array}{l}\text { DCB in aqueous phase } \\
(\mathrm{ppm})\end{array}$ & 115.8 & 98.99 & 81.6 & 61.5 & 27.1 & 17.4 \\
$\begin{array}{l}\text { TCE in aqueous phase } \\
(\mathrm{ppm})\end{array}$ & 0. & 166.3 & 342.6 & 665.0 & 990.0 & 1100 \\
$\begin{array}{l}\text { Lost of TCE } \\
(\mathrm{ppm})\end{array}$ & 0. & 0. & 78.2 & 161.0 & 312.5 & 465.3 \\
$\begin{array}{l}\text { DCB in organic phase } \\
(\mathrm{ppm})\end{array}$ & 88.2 & 105.0 & 122.4 & 142.5 & 176.9 & 186.6 \\
$\begin{array}{l}\text { TCE in organic phase } \\
(\mathrm{ppm})\end{array}$ & 0 & 30.5 & 46.4 & 122.5 & 744.7 & 1683. \\
$\begin{array}{l}\text { Mole of DCB } \\
\left(10^{-6}\right)\end{array}$ & 0.600 & 0.714 & 0.833 & 0.969 & 1.203 & 1.269 \\
$\begin{array}{l}\text { Mole of TCE } \\
\left(10^{-6}\right)\end{array}$ & 0 & 0.2331 & 0.354 & 0.935 & 5.685 & 12.85 \\
$\begin{array}{l}\text { Xdcb in organic phase } \\
(\text { Mole fraction) }\end{array}$ & 1. & 0.754 & 0.702 & 0.509 & 0.175 & 0.090 \\
\begin{tabular}{l} 
s / S of DCB \\
\hline
\end{tabular} & 1. & 0.855 & 0.705 & 0.531 & 0.234 & 0.150 \\
\hline
\end{tabular}


Table 5.4. Effect of TCE on the Solubilities of 1,2,4-Tichlorobenzene

\begin{tabular}{lllllll}
\hline Sample No. & 1 & 2 & 3 & 4 & 5 & 6 \\
\hline $\begin{array}{l}\text { Total DCB added } \\
(\mathrm{ppm})\end{array}$ & 72. & 72. & 72. & 72. & 72. & 72. \\
$\begin{array}{l}\text { Total TCE added } \\
(\mathrm{ppm})\end{array}$ & 0. & 275. & 550. & 1100. & 2200. & 3300 \\
$\begin{array}{l}\text { DCB in aqueous phase } \\
(\mathrm{ppm})\end{array}$ & 28.6 & 23.4 & 20.3 & 11.8 & 2.12 & 0.54 \\
$\begin{array}{l}\text { TCE in aqueous phase } \\
(\mathrm{ppm})\end{array}$ & 0. & 231. & 462. & 879. & 1040. & 1046. \\
$\begin{array}{l}\text { Lost of TCE } \\
(\mathrm{ppm})\end{array}$ & 0. & 34.6 & 69.3 & 131.8 & 156.0 & 156.9 \\
$\begin{array}{l}\text { DCB in organic phase } \\
(\mathrm{ppm})\end{array}$ & 43.4 & 48.6 & 51.7 & 60.2 & 69.9 & 71.5 \\
$\begin{array}{l}\text { TCE in organic phase } \\
(\mathrm{ppm})\end{array}$ & 0 & 9.4 & 18.7 & 89.2 & 1.00 & 2.097 \\
$\begin{array}{l}\text { Mole of DCB } \\
\left(10^{-6}\right)\end{array}$ & 0.239 & 0.268 & 0.285 & 0.332 & 0.385 & 0.394 \\
$\begin{array}{l}\text { Mole of TCE } \\
\left(10^{-6}\right)\end{array}$ & 0 & 0.071 & 0.143 & 0.680 & 7.664 & 16.01 \\
$\begin{array}{l}\text { Xdcb in organic phase } \\
(\text { Mole fraction) }\end{array}$ & 1. & 0.790 & 0.666 & 0.328 & 0.048 & 0.024 \\
\begin{tabular}{l} 
s / of DCB \\
\hline
\end{tabular} & 1. & 0.817 & 0710 & 0.413 & 0.074 & 0.019 \\
\hline
\end{tabular}


(1984) noticed that equation (13) may break down if hydrophilic compounds were included in the mixture. From our results, it appears that the small positive deviation $\left(s_{i} / S_{i}>\left(x_{i}\right)_{o}\right)$ might exist because the loss of TCE ( appreciable) was considered (see Tables 5.1 to 5.4), but not that of chlorobenzene.

\subsubsection{Mixtures of Solid Chlorobenzene and TCE}

Our results indicated that TCE did not significantly affect solubility of chlorobenzene which was solid at $25^{\circ} \mathrm{C}$ until the chlorobenzene dissolves in the TCE phase. It is because that liquid solutes are usually miscible with one another, and as a result, they are able to interact within the organic phase. Solids, on the other hand, tend not to mix at the molecular level, and to a good approximation, they behave independently. Hence, the solubility of a mixture of solids is frequently the sum of the solubilities of its components (Yalkowsky, 1992).

However, the mixture of liquid and solid can exhibit complex behavior which varies with properties of compounds and proportion of liquid and solid in the mixture. If the liquid components in the mixture dissolve the solid components, then the mixture behaves as a typical liquid and liquid mixture (Banerjee, 1984).

Since our interest was mainly focused on the co-solute effect of TCE on the solubility of chlorobenzene, only a few data available to analyze the case where TCE dissolved the solid chlorobenzene. Predicting the solubilities of the higher-melting-point components of those mixture in water is necessary 
to estimate hypothetical supercooled liquid solubilities. The calculated hypothetical supercooled liquid solubilities at $25^{\circ} \mathrm{C}$ are presented in Table 5.5 showing that supercooled liquid solubility can be orders of magnitude larger than the solid solubility. The estimated results (from equation (17)) were same as that by using the equation from Shiu et al (1988):

$$
S_{i}^{s c l}=S_{i} e^{6.8\left(\frac{M P}{T}-1\right)}
$$

where MP is melting point $\left({ }^{\circ} \mathrm{K}\right)$ and $\mathrm{T}$ is the system temperature $\left({ }^{\circ} \mathrm{K}\right)$.

The results of applying equation (19) is given in Table 5.6. Table 5.7 shows comparison between experimental solubilities and predicted solubilities in the mixtures. One source of errors in the calculation is the melting point correction, equation (17); it is only an estimation method. My results indicate that equation (17) underestimates aqueous solubility of mixture as long as the aqueous solubility of compound is larger than $20 \mathrm{ppm}$, and overestimates solubility of mixture where the compound has very low aqueous solubility (below $10 \mathrm{ppm}$ ). Same trend can be observed from the results of Vadas (1991).

It is very interesting to note the experimental results from Murphy et al. (1987): "The solubility of the polychlorinated biphenyls (PCBs) in water is shown to be significantly lower when a solution of the PCBs is prepared by adding an organic solution (acetone, methanol, etc.) to water." This result means equation (13) can also be used, to a certain extent, to predict the behavior of mixture of polar compounds. 
Table 5.5. Hypothetical Supercooled Liquid Solubility Estimates at $25^{\circ} \mathrm{C}$

\begin{tabular}{lccc}
\hline Compound & $\begin{array}{c}\text { Melting } \\
\text { Point } \\
\left({ }^{\circ} \mathrm{C}\right)\end{array}$ & $\begin{array}{c}\text { Pure Compound } \\
\text { Solubility }(S)\end{array}$ & $\begin{array}{c}\text { Supercoold Liquid* } \\
(\mathrm{ppm})\end{array}$ \\
\hline Solubility Estimate $\left(S^{s c l}\right)$ \\
1,4-Dichlorobenzene & 53.1 & $76.7 \pm 3.9$ & 145.4 \\
1,2,3-Trichlorobenzene & 53 & $19.3 \pm 0.7$ & 36.5 \\
1,3,5-Trichlorobenzene & 63 & $9.4 \pm 0.4$ & 22.3 \\
\hline
\end{tabular}

* Calculated from equation (17) 
Table 5.6. Aqueous Solubility Results for 3 Solid Chlorobenzenes in Mixture

\begin{tabular}{lccc}
\hline Compound & $\begin{array}{c}\text { Measured } \\
\text { Concentration } \\
\text { in Aqueous Phase }\end{array}$ & $\begin{array}{c}\text { Mole Fraction of } \\
\text { Compound }\end{array}$ & $\begin{array}{c}\text { Predicted } \\
\text { Concentration* } \\
\left(s_{i} / S_{i}^{s c l}\right)\end{array}$ \\
\hline 1,4-Dichlorobenzene & 66.6 & 0.24 & 0.46 \\
1,4-Dichlorobenzene & 30.9 & 0.08 & 0.21 \\
$1,2,3$-Trichlorobenzene & 16.3 & 0.22 & 0.45 \\
$1,2,3-$ Trichlorobenzene & 12.4 & 0.16 & 0.34 \\
$1,3,5$-Trichlorobenzene & 5.59 & 0.23 & 0.25 \\
$1,3,5$-Trichlorobenzene & 1.68 & 0.14 & 0.08 \\
\hline
\end{tabular}

* Calculated from equation (19) 
Table 5.7. Solubility for Mixtures of Chlorobenzene and TCE

\begin{tabular}{|c|c|c|c|}
\hline Compound & $\begin{array}{c}\text { Measured } \\
\text { Concentration } \\
\text { ( ppm ) }\end{array}$ & $\begin{array}{l}\text { Mole Fraction of } \\
\text { Compound } \\
\text { in Organic Phase }\end{array}$ & $\begin{array}{c}\text { Predicted } \\
\text { Concentration } \\
\text { ( ppm ) }\end{array}$ \\
\hline 1,4-Dichlorobenzene & 66.6 & 0.24 & 34.0 \\
\hline 1,4-Dichlorobenzene & 30.9 & 0.08 & 11.8 \\
\hline 1,2,3-Trichlorobenzene & 16.3 & 0.22 & 8.05 \\
\hline 1,2,3-Trichlorobenzene & 12.4 & 0.16 & 5.84 \\
\hline 1,3,5-Trichlorobenzene & 5.59 & 0.23 & 5.14 \\
\hline 1,3,5-Trichlorobenzene & 1.68 & 0.14 & 3.11 \\
\hline
\end{tabular}




\subsection{Phenomenon Explanation and Application}

The results from this study may apply more directly to groundwater where solubility may control the transport of contaminants. Consider for example, a phenomenon is that organic compounds are rarely found in groundwater at concentrations approaching their solubility limits, even when organic liquid phases are known or suspected to be present. The observed concentrations are usually more than a factor of $\mathbf{1 0}$ lower than the solubility. Mackay et al. (1985) believed this fact was due to the diffusional limitations of dissolution and the dilution of the dissolved organic contaminants by dispersion. Our experimental results suggest an alternative explanation. Organic contaminants in groundwater almost always are in mixtures (e.g., gasoline), and that in equilibrium conditions the solubility of a compound in the mixture generally lower than that of pure compound.

The application of these results can be also directly used to discuss the toxicity of organic mixture in water. For example, solubility may cause a substantial change in toxicity; it has been shown (Sugatt et al., 1984) that in the absence of biological interactive effects, the toxicity of a component in a saturated mixture of liquids will be equal to or less than that of a corresponding solution of its most toxic component. In contrast, for the solutions derived from a mixture of solids, the toxicity will equal or exceed that of a corresponding saturated solution of its most toxic component. 


\subsection{Real or Apparent Solubility}

While attempting our first set of experiments, we discovered that similar problems had been encountered in the oil industry (Peake and Hodgson, 1966 and 1967). Results from earlier studies on petroleum hydrocarbons indicate that it is extremely easy to form emulsions or colloids, and that if these form, apparent solubilities measured would be dependent on availability of solute (directly proportional) and inversely proportional to settling time. Hodgson and Peake (1966 and 1967) define accommodation (difference between apparent and actual solubility) to be a function of hydrocarbon supply, shaking period, settling time and filter pore size. Thus, they concluded that it was almost impossible to find real solubility of hydrocarbons. However, a half year setting period results indicated that setting effects were most pronounced during the first few days; only minor changes beyond 10 days for petroleum hydrocarbons (Peake and Hodgson, 1966 and 1967). We avoid such problems when we went to longer settling times (30 days).

The phenomenon that the apparent solubility will increase with the amount of solute used to prepare the saturated solution was also noted by James (1986). He believed that this was caused by impurity of sparingly soluble solute and limitation of analytical method. For example, if an impurity is more soluble than the compound under investigation, it will be preferentially dissolved, and if the method of analysis is unable to distinguish between the substance and its impurity, the apparent solubility will increase with the amount of solute used to prepare the saturated solution. It follows that for substances having low solubilities, any 
advantage gained by increasing the quantity of solute will be counterbalanced by the increased error arising from the impurity. One method for investigating the amount of impurities present is by examining the melting point of the compound of interest. Impure compounds, which generally have lower melting points than those of pure compounds, will have correspondingly higher solubilities. In general, all other factors being equal, a $100^{\circ} \mathrm{C}$ difference in melting point translates to a 10 -fold difference in solubility (Banerjee, 1984). However, as most experiments in this study were conducted by using the highest grade solutes (+98\%) possible, impurity was not an important factor in this study.

In addition to the formation of emulsions and impurities, the ratio of water to organic phase volumes can also influence solubilities of mixtures. Shiu et al. (1988) believed that the general solubility theory cannot applied to hydrophobic organic compounds and therefore they asserted: "Solubility" of mixtures is a function of both the composition of the organic mixture and the ratio of water to organic phase volumes. The paper further explained that: an important and often unappreciated factor is that the "solubility" of such mixtures depends not only on the composition and properties of the organic mixtures but also on the water-to-organic-liquid volume ratio. 


\section{Chapter 6}

\section{CONCLUSION}

The experimental results from this study demonstrate that solubility in water of liquid mixture is affected by the composition of the mixture. The solubilities of chlorobenzenes which are liquid at $25^{\circ} \mathrm{C}$ decrease with increasing concentration of TCE. The fits of model indicate that the mixture of TCE and chlorobenzene is near ideal behavior. The solubilities of solid chlorobenzenes appear to be independent of the concentration of TCE in the aqueous phase, in another words, TCE does not decrease solubility of chlorobenzene which is solid at $25^{\circ} \mathrm{C}$ unless chlorobenzene dissolves in the TCE phase. That is, excess TCE, above its solubility, must be present. Consequently, we can conclude from our experimental results that measured aqueous concentrations below solubility are not an indication that an organic phase is not present. A mixture of organic compounds can form a separate phase when aqueous concentrations are still below solubility. Therefore, the equation (13) based on ideal behavior may be acceptable for most field-scale applications.

The measurement of aqueous solubility of chlorobenzene is very difficult due to the existence of accommodation. Thus, most published solubility data for chlorobenzenes are apparent solubilities (i.e., a function of experimental procedures). The experimental results shows that the degree of accommodation is linearly proportional to availability of chlorobenzene. 
Hence, for a practical perspective, using apparent solubility to model the transport of hydrophobic organic compounds might be more applicable since almost all the aquifers involve more or less advective flow and real solubility may never be achieved. However, the problem is that apparent solubility are a function of a variety of factors, such as amount of solute, contact time, mechanical agitation. In order to assign a value to the accommodation level of a hydrophobic carbon or mixture of organic carbons, conditions must be carefully defined. In general, regardless of real or apparent solubility, knowing the composition of the organic phase is essential in assessing the fate of organic compounds in the aquatic environment. 


\section{REFERENCES}

1. Banerjee, Sujit, Solubility of Organic Mixtures in Water, Environmental Science and Technology, 18, 587-591, 1984.

2. Banerjee, Sujit, Samuel H. Yalkowsky, and Shri C. Valvani, Water Solubility and Octanol/Water Partition Coefficients of Organics. Limitations of Solubility-Partition Coefficient Correlation, Environmental Science and Technology, 14, 1227-1229, 1980.

3. Billington, James W., Guo-Lan Huang, Foon Szeto, Wan Ying Shiu, and Donald Mackay, Preparation of Aqueous Solutions of Sparingly Soluble Organic Substances I. Single Component Systems, Environmental Toxicology and Chemistry, 7, 117-124, 1988.

4. Bohon, Robert L. and W. F. Claussen, The Solubility of Aromatic Hydrocarbons in Water, Am. Chem. Soc., 73, 1571-1578, 1951.

5. Burris, David R. and William G. MacIntyre, Water Solubility Behavior of Binary Hydrocarbon Mixtures, Environmental Toxicology and Chemistry, 4, 371-377, 1985 .

6. Burris, David R. and William G. MacIntyre, A Thermodynamic Study of Solutions of Liquid Hydrocarbon Mixtures in Water, Geochimica et Cosmochimica Acta, 50, 1545-1549, 1986.

7. Chey, Willie and George V. Calder, Method for Determining Solubility of Slightly Soluble Organic Compounds, Journal of Chemical and Engineering Data, 17, 199-200, 1972.

8. Eganhouse, Robert P. and John A. Calder, The Solubility of Medium Molecular Weight Aromatic Hydrocarbons and the Effects of Hydrocarbon Co-solutes and Salinity, Geochimica et Cosmochimica Acta, 40, 555-561, 1976.

9. James, Kenneth C., in Solubility and Related Properties, p. 46, 1986.

10. Lane, William F. and Raymond C. Loehr, Estimating the Equilibrium Aqueous Concentrations of Polynuclear Aromatic Hydrocarbons in Complex Mixtures, Environmental Science and Technology, 26, 9883-990, 1992.

11. Lee, Linda S., P. Suresh C., and Itaru Okuda, Equilibrium Partitioning of Polycyclic Aromatic Hydrocarbons from Coal Tar into Water, Environmental Science and Technology, 26, 2110-2115, 1992.

12. Lee, Linda S., Mats Hagwall, Joseph J. Deifino, and P. Suresh C. Rao, and Sujit Banerjee, Calculation of Water Solubility of Organic Compounds with 
UNIFAC-Derived Parameters, Environmental Science and Technology, 19, 369-370, 1985.

13. Leinonen, Paul J. and Donald Mackay, The Multicomponent Solubility of Hydrocarbons in Water, The Canadian Journal of Chemical Engineering, 51, 230-233, 1973.

14. Leinonen, Paul J., Donald Mackay, and C. R. Phillips, A Correlation for the Solubility of Hydrocarbons in Water, The Canadian Journal of Chemical Engineering, 49, 288-290, 1971.

15. Mackay, Donald and Wan Ying Shiu, Aqueous Solubility of Polynuclear Aromatic Hydrocarbons, Journal of Chemical and Engineering Data, 22, 399-402, 1977.

16. Mackay, Donald and Wan Ying Shiu, A Critical Review of Henry's Law Constants for Chemicals of Environmental Interest, J. Phys. Chem. Ref. Data, 10, 1175-1199, 1981.

17. Mackay, Donald, Wan Ying Shiu, and Kuo Ching Ma, in Illustrated Handbook of Physical-chemical Properties and Environmental Fate for Organic Chemicals, vol. 1, 1992.

18. Mackay, D., R. Mascarenhas, W. Y. Shiu, S. C. Valvani, and S. H. Yalkowsky, Aqueous Solubility of Polychlorinated Biphenyls, Chemosphere, 9, 257-264, 1980.

19. Mackay, Douglas M., Paul V. Roberts, and John A. Cherry, Transport of Organic Contaminants in Groundwater., Environmental Science and Technology, 19, 384-392, 1985.

20. May, Willie E., Stanley P. Wasik, and David H. Freeman, Determination of the Aqueous Solubility Behavior of Polycyclic Aromatic Hydrocarbons in Water, Analytical Chemistry, 50, 1978.

21. May, Willie E., Stanley P. Wasik, and David H. Freeman, Determination of the Aqueous Solubility of Polynuclear Aromatic Hydrocarbons by a Coupled Column Liquid Chromatographic Technique, Analytical Chemistry, 50, 175179, 1978.

22. McAuliffe, Clayton, Solubility in Water of Paraffin, Cycloparaffin, Olefin, Acetylene, Cycloolefin, and Aromatic Hydrocarbons, The Journal of Physical Chemistry, 70, 1267-1275, 1966.

23. McNally, M. E. and R. L. Grob, Determination of the Solubility Limits of Organic Priority Pollutants by Gas Chromatographic Headspace Analysis, Journal of Chromatography, 260, 23-32, 1983. 
24. Miller, Michele M., Samir Ghodbane, Stanley P. Wasik, Yadu B. Tewari, and Daniel E. Martire, Aqueous Solubilities, Octanol/Water Partition Coefficients, and Entropies of Melting of Chlorinated Benzenes and Biphenyls, Journal of Chemical and Engineering Data, 29, 184-190, 1984.

25. Morris, Kenneth R., Robert Abramowitz, Rodolfo Pinal, Peg Davis, and Samuel H. Yalkowsky, Solubility of Aromatic Pollutants in Mixed Solvents, Chemosphere, 17, 285-298, 1988.

26. Murphy, Thomas J., Michael D. Mullin, and Joseph A. Meyer, Equilibration of Polychlorinated Biphenyls and Toxaphene with Air and Water, Environmental Science and Technology, 21, 155-162, 1987.

27. Nirmalakhandan, Nagamany N. and Richard E. Speece, Prediction of Aqueous solubility of Organic Chemicals Based on Molecular Structure. 2. Application to PNAs, PCBs, PCDDs, etc., Environmental Science and Technology, 23, 708-713, 1989.

28. Peake, Eric and G. W. Hodgson, Alkanes in Aqueous Systems. I. Exploratory Investigations on the Accommodation of C20-C30 n-Alkanes in Distilled Water and Occurrence in Nature Water System, The Journal of the American Oil Chemists' Society, 43, 215-222, 1966.

29. Peake, Eric and G. W. Hodgson, Alkanes in Aqueous Systems. II. The Accommodation of C12-C36 n-Alkanes in Distilled Water, The Journal of the American Oil Chemists' Society, 44, 696-702, 1967.

30. Pinal, Rodolfo, P. Suresh C. Rao, Linda S. Lee, Patricia V. Cline, and Samuel H. Yalkowsky, Cosolvency of Partially Miscible Organic Solvents on the Solubility of Hydrophobic Organic Chemicals, Environmental Science and Technology, 24, 639-647, 1990.

31. Ruelle, Paul, Michel Buchmann, Ho Nam-Tran, and Ulrich W. Kesselring, Application of the Mobile Order Theory to the Prediction of Aqueous Solubility of chlorinated Benzenes and Biphenyls, Environmental Science and Technology, 27, 266-270, 1993.

32. Shiu, Wan Ying, Aila Maijanen, Anita L. Y. Ng, and Donald Mackay, Preparation of Aqueous Solutions of Sparingly Soluble Organic Substances II. Multicomponent Systems-Hydrocarbon Mixtures and Petroleum Products, Environmental Toxicology and Chemistry, 7, 125-137, 1988.

33. Sittig, Marshall, in Handbook of Toxic and Hazardous Chemicals, 1981.

34. Sugatt, Richard H., Dean P. O'Grady, and Sujit Banerjee, Toxicity of Organic Mistures Saturated in Water To Daphnia Magna. Effect of Compositional Changes, Chemosphere, 13, 11-18, 1984. 
35. Tewari, Y. B., D. E. Martire, S. P. Wasik, and M. M. Miller, Aqueous Solubilities and Octanol-Water Partition Coefficients of Binary Liquid Mixtures of Organic Compounds at $25^{\circ} \mathrm{C}$, Journal of Solution Chemistry, 11, 435-444, 1982.

36. Vadas, G. G., W. G. MacIntyre, and D. R. Burris, Aqueous Solubility of Liquid Hydrocarbon Mixtures Containing Dissolved Solid Components, Environmental Toxicology and Chemistry, 10, 633-639, 1991.

37. Velapoldi, Rance A., Patricia A. White, and Willie E. May, Spectrofluorimetric Determination of Polycyclic Aromatic Hydrocarbons in Aqueous Effluents from Generator Columns, Analytical Chemistry, 55, 18961901, 1983.

38. Yalkowsky, Samuel H., Personal communication, 1991.

39. Yalkowsky, Samuel H. and Sujit Banerjee, in Aqueous Solubility, 1992.

40. Yalkowsky, Samuel H., Robert J. Orr, and Shri C. Valani, Solubility and Partitioning 3. The Solubility of Halobenzenes in Water, Ind. Eng. Chem. Fundam, 18, 351-353, 1979.

41. Yalkowsky, Samuel. H. and Shri C. Valvani, Solubility and Partitioning I: Solubility of Nonelectrolytes in Water, Journal of Phyarmaceutical Sciences, 69, 912-922, 1980.

42. Yalkowsky, S. H., S. C. Valvani, and D. Mackay, Estimation of the Aqueous solubility of Some Aromatic compounds, Residue Reviews, 85, 43-55, 1983. 